Article

\title{
Finite Element Analysis of Liquefied Ammonia Tank for Mobility Vehicles Employing Polymers and Composites
}

\author{
Alvin Reynaldo ${ }^{1}$, Hari Sidik Pramono ${ }^{1}$, Sigit Puji Santosa ${ }^{1}$ and Muhammad Aziz ${ }^{2, *(1)}$ \\ 1 Mechanical and Aerospace Engineering, Institut Teknologi Bandung, Jl. Ganesha 10, \\ Bandung 40132, Indonesia; alvinreynaldo@gmail.com (A.R.); harisidikp@gmail.com (H.S.P.); \\ sigit.santosa@itb.ac.id (S.P.S.) \\ 2 Institute of Industrial Science, The University of Tokyo, 4-6-1 Komaba, Meguro-ku, Tokyo 153-8505, Japan \\ * Correspondence: maziz@iis.u-tokyo.ac.jp
}

Received: 20 July 2020; Accepted: 4 October 2020; Published: 13 October 2020

\begin{abstract}
Hydrogen has attracted global attention as a clean secondary energy source and has numerous possible applications, including fuel for vehicles. To store the hydrogen effectively, ammonia is considered promising due to high hydrogen density, stability, and total energy efficiency. Adopting ammonia as a fuel in vehicles requires a proper fuel tank design to fulfill the required volumetric content and safety standards, without neglecting the economic objectives. In general, a type-IV pressure vessel is utilized as a fuel tank because it is the lightest one, compared to other types of pressure vessel. This paper focuses on the effort to develop a lightweight type-IV ammonia pressure vessel designed for mobility vehicles. The material combination (liner and composite) and composite stacking sequence are analyzed for both burst and impact tests by using a finite element method. Two polymer materials of polyethylene terephthalate (PET) and polypropylene (PP) are evaluated as the liner considering their ultimate tensile strength, density, cost, and compatibility with ammonia, while carbon-fiber-reinforced polymer (CFRP) and glass-fiber-reinforced polymer (GFRP) are adopted as composite skins. In addition, five composite stacking sequences are analyzed in this study. Von Mises stress and Hashin's damage initiation criteria are used to evaluate the performance of liner and composite, respectively. As the results, PP-based pressure vessels generate lower stress in the liner compared to PET-based vessels. In addition, CFRP-based pressure vessels have a higher safety margin and are able to generate lower stress in the liner and lower damage initiation criteria in the composite skin. The material combination of PP-CFRP with a stacking sequence of $[90 / \pm 30 / 90]_{3 s}$ gives the lowest maximum stress in the liner during the burst test, while, for the impact test, the stacking sequence of $[90 / \pm \theta / 90]_{3 \mathrm{~s}}$ is considered the most appropriate option to realize a lower stress at the liner, although this tendency is relatively small for vessels with PP liner.
\end{abstract}

Keywords: ammonia; type-IV pressure vessel; mobility vehicle; finite element method; burst test; impact test

\section{Introduction}

According to the global warming of $1.5^{\circ} \mathrm{C}$ issued by the Intergovernmental Panel on Climate Change (IPCC), the average global temperature has increased $0.86{ }^{\circ} \mathrm{C}$ for the decade of $2006-2015$ above the pre-industrial baseline due to the emission of greenhouse gases (GHGs) [1]. If this condition keeps continuing, serious global warming is predicted to occur and potentially cause climate change [2]. Fossil fuels have contributed up to $65 \%$ of the total GHG emissions in 2014, and approximately $23 \%$ of $\mathrm{CO}_{2}$ was emitted from the transportation sector [3]. Therefore, an immediate transformation in the 
energy system to utilize clean energy sources instead of fossil fuels is required to give the solution to this global warming problem.

Hydrogen $\left(\mathrm{H}_{2}\right)$ has been known as a clean energy carrier because its oxidation only produces water $\left(\mathrm{H}_{2} \mathrm{O}\right)$ [4]. However, hydrogen has a very low density $(0.0813 \mathrm{~g} / \mathrm{L})$ and energy density (lower heating value of $0.01005 \mathrm{MJ} / \mathrm{L}$ ) at $25^{\circ} \mathrm{C}$ and 1 bar. The hydrogen compressed at $700 \mathrm{bar}$, which is currently adopted for hydrogen-fueled vehicles, shows a higher energy density of $5.6 \mathrm{MJ} / \mathrm{L}$. However, this is still significantly lower than gasoline (34.2 MJ/L) and methanol (15.6 MJ/L) [5]. Due to this very low volumetric energy density, effective hydrogen storage method is urgently demanded [6]. Hydrogen storage can be carried out through several methods, including physical (compression and liquefaction), chemical (metal and chemical hydrides), and adsorption (nanoporous carbons and metal-organic frameworks) $[7,8]$. Among those hydrogen storage methods, ammonia $\left(\mathrm{NH}_{3}\right)$ is considered very efficient due to its high gravimetric and volumetric hydrogen densities, which are $17.8 \mathrm{wt} \%$ and $120.3 \mathrm{~kg}-\mathrm{H}_{2} / \mathrm{m}^{3}$, respectively [9]. In case of Japan, as one of the key players in hydrogen adoption in energy system, both government and industries are currently focusing on the effort to adopt three main hydrogen storage methods, which are liquid hydrogen, toluene-methylcyclohexane (MCH) cycle, and ammonia, due to their economic performance, technological maturity, and other aspects [10]. A comparison study among those three kinds of hydrogen storages, conducted by Wijayanta et al. [11], indicated that ammonia has the highest total energy efficiency (covering synthesis, storage/transportation, and utilization) and economic performance. Ammonia can be synthesized via different routes of conversion, including Haber-Bosch, electrochemical, thermochemical, photochemical, and membrane reactor. About $85 \%$ of total ammonia production is currently carried out by adopting the Haber-Bosch process, in which the synthesis is conducted at relatively high temperatures and pressure of $400-500{ }^{\circ} \mathrm{C}$ and $10-30 \mathrm{MPa}$, respectively. Through process optimization and the development of the catalyst, these conditions can be lowered [12]. Cui et al. [13] have developed an iron-based cyclic process, resulting in highly selective and efficient ammonia synthesis.

Ammonia has been widely used, especially as fertilizer. In addition, due to its high potential as hydrogen storage and fuel, ammonia is also applicable in many other sectors, including power generation and transportation. The infrastructures for ammonia production, storage, and distribution have already existed, resulting in a smooth energy transition. Some works to utilize ammonia in transportation have been carried out [14,15]. Ezzat and Dincer [16] have performed an exergoeconomic analysis and optimization of hybrid fuel cell vehicles using ammonia as the energy source. They introduced an integrated propulsion system consisting of an internal combustion engine (ICE), proton exchange membrane fuel cell, and ammonia dissociation separation unit. The integrated system could achieve a maximum exergy efficiency of up to $61.3 \%$ with a cost of $7.8 \mathrm{USD} / \mathrm{h}$ at a density of $1348 \mathrm{~mA} / \mathrm{cm}^{2}$. In addition, liquid ammonia also offers a much safer utilization in the vehicle compared to the compressed hydrogen that has higher explosion risk and leakage (embrittlement) [17].

The application of ammonia as a fuel for an ICE is beneficial from the energy point of view due to its high octane rate, which is 110-130 [18]. Novel catalysts, such as $\mathrm{BaO} / \mathrm{Ni} / \mathrm{Sm}_{2} \mathrm{O}_{3} / \mathrm{MgO}$, have been developed to decompose the ammonia externally, achieving an efficiency of 57.3\% [19]. Ammonia can also be used directly for the fuel cells, including the alkaline fuel cell (AFC), alkaline membrane fuel cell (AMFC), and the solid-oxide fuel cell (SOFC), leading to higher energy efficiency in the transportation sector [20].

Adopting ammonia as a fuel in vehicles needs a proper fuel tank design to facilitate its required volumetric content, safety, and economy. Relevant fuel tank designs that have been developed and used in vehicles include propane, hydrogen, and gasoline. In terms of boiling temperature and condensation pressure, ammonia has similar characteristics with propane [21]. Therefore, it is generally mentioned that ammonia can be stored using the existing storage infrastructures (e.g., tank) used for propane [22]. However, both materials have different physical characteristics, including flammability limits, autoignition temperature, and corrosivity. Compared to propane, ammonia has higher auto-ignition temperature $\left(651^{\circ} \mathrm{C}\right.$ compared to $\left.470{ }^{\circ} \mathrm{C}\right)$ and flammability limit (15-28 compared 
to 2.1-10.1). In addition, ammonia is corrosive to copper, brass, and galvanized components. Ammonia can be stored in a liquid condition via two different methods: compression and refrigeration. In the former, ammonia is stored at an elevated pressure, but permitting the temperature to be ambient, for example, a pressure of $0.99 \mathrm{MPa}$ at a temperature of $25^{\circ} \mathrm{C}$. The latter method is cooling down the ammonia until it reaches its condensation temperature under atmospheric pressure $\left(-33^{\circ} \mathrm{C}\right)$. However, considering that the surrounding temperature can reach nearly $50^{\circ} \mathrm{C}$, the tank internal pressure might approach around $2 \mathrm{MPa}$ (numerically, when the temperature reaches $47^{\circ} \mathrm{C}$, the internal pressure increases to $1.87 \mathrm{MPa}$ ).

Complete combustion of ammonia leads to the formation of nitrogen and water vapor, and the specific energetic cost of ammonia is less than gasoline and natural gas, based on the report issued by the World LPG Association (WLPGA) [23]. On the other hand, propane and liquefied petroleum gas (LPG, a mixture of propane and butane) have been globally adopted as fuel for vehicles. As propane/LPG and ammonia have similar physical properties, especially related to the boiling temperature and condensation pressure [22], some studies mentioned the probability to use the propane/LPG tank for ammonia in vehicles $[11,21,24]$. They are basically distributed and stored at the filling stations as pressurized gas having pressure ranging from 0.6 to $1 \mathrm{MPa}$. However, the majority of the propane/LPG tanks in the vehicle are adopting metal materials, including aluminum and steel [25], leading to the heavier vehicle load.

Kamal et al. have developed and analyzed a pressure vessel that was used in seawater reverse osmosis [26]. In their study, several composite layups have been calculated and compared to the stainless steel-made pressure vessel and simulated by using finite element method. As the results of their study, relatively low discrepancy (less than 2.2\%) has been obtained. However, the design of dome and liner material was not taken into consideration. In addition, in designing the pressure vessel, several loads need to be considered [27].

To the best knowledge of the authors, although there are many literatures dealing with hydrogen storage, the work focusing on composite-based ammonia storage, especially type-IV ammonia tank for vehicles, could not be found (based on Scopus and Web of Science databases). In this paper, preliminary design and analysis of composite-based tank to store liquid ammonia for vehicles is proposed. It is expected that by employing combined polymer and composite, a lighter and corrosion-free ammonia pressure vessel (longer lifetime) can be realized. In order to analyze the effect of materials and their combination, polyethylene terephthalate (PET) and polypropylene (PP) are adopted and compared as a tank liner, while carbon-fiber-reinforced polymer (CFRP) and glass-fiber-reinforced polymer (GFRP) are introduced as the reinforcing composite. The objective of this study is to obtain and clarify the optimum composite direction and amount of composite stacking needed in each combination of the materials. Burst and impact load tests are used in determining the performance of the tank.

The paper is organized as follows. Section 2 describes the methodology, including the developed design and method of optimization used in this research. Section 3 explains the adopted finite element method and the governing equation. Section 4 presents the result of simulation and the discussion. Section 5 is the author's conclusion.

\section{Methodology}

\subsection{Pressure Vessel Design}

The pressure vessel is designed by considering the capacity of the pressure vessel, head of the pressure vessel, ammonia properties, and compatibility of ammonia with the pressure vessel material. Liquid ammonia properties are shown in Table 1. 
Table 1. Properties of liquid ammonia [28].

\begin{tabular}{ccc}
\hline Properties & Units & Values \\
\hline Density at STP & $\mathrm{kg} / \mathrm{m}^{3}$ & 0.769 \\
Melting point & ${ }^{\circ} \mathrm{C}$ & -77.73 \\
Boiling point at $1 \mathrm{~atm}$ & ${ }^{\circ} \mathrm{C}$ & -33.4 \\
Vapor pressure at $20{ }^{\circ} \mathrm{C}$ & $\mathrm{kPa}$ & 857.1 \\
Auto ignition temperature & ${ }^{\circ} \mathrm{C}$ & 651 \\
Heat of combustion & $\mathrm{MJ} / \mathrm{L}$ & 11.2 \\
Thermal conductivity & $\mathrm{mW} / \mathrm{m} \cdot \mathrm{K}$ & 22.19 \\
Critical temperature & ${ }^{\circ} \mathrm{C}$ & 132.4 \\
Critical pressure & $\mathrm{MPa}$ & 11.28 \\
Critical density & $\mathrm{kg} / \mathrm{m}^{3}$ & 240 \\
Liquid Density at $70{ }^{\circ} \mathrm{C}$ & $\mathrm{kg} / \mathrm{m}^{3}$ & 551 \\
Liquid Pressure at $70{ }^{\circ} \mathrm{C}$ & $\mathrm{MPa}$ & 2.8 \\
\hline
\end{tabular}

The capacity of the pressure vessel design is based on the work conducted by Zamfirescu et al. [18]. The paper states that by using an $\mathrm{H}_{2} \mathrm{ICE}$ Ford Focus as the testing vehicle, the storage tank for hydrogen with a volume of $217 \mathrm{~L}$ is required to obtain the driving range of $298 \mathrm{~km}$. In the case of ammonia as a fuel, the prototype tank having volume of $76 \mathrm{~L}$ may reach the driving range of $430 \mathrm{~km}$. In addition, Toyota Mirai, Honda Clarity, and Mercedes GLC are the hydrogen cars which use two pressure vessels to store the fuel, and each pressure vessel differs in size to get highly efficient packaging and high capacity [29]. Considering that two tanks having a total volume of $76 \mathrm{~L}$ are installed in the vehicle, an ammonia storage tank with a volume of $37.2 \mathrm{~L}$ is designed and its performance is analyzed in this study.

After determining the tank volume, the pressure vessel head or dome is determined. There are several types of pressure vessels head listed in the American Society of Mechanical Engineering (ASME) Section VIII division II. They are torispherical, cylindrical, and spherical or hemispherical tanks [30]. Lawate et al. has researched the optimum head of pressure vessel [31] and found that the most optimum pressure vessel from several available heads of pressure vessel is the spherical head, based on the maximum stress and deformation in the head of the pressure vessel. The Von Mises stresses of elliptical and torispherical heads are 2.5 and 3.58 times of the spherical head, respectively. The maximum deformations of elliptical and torispherical heads are 9.26 and 9 times of the spherical head, respectively.

The tank is basically designed based on the work of Zhang et al. [32], which is type-IV pressure vessel model. The base model was developed for the hydrogen with a capacity of $70 \mathrm{MPa}$. The design was modified to fit into the tank design. Figure 1 shows the dimensions of the developed type-IV pressure vessel for liquid ammonia. The vessel has a length of $902.4 \mathrm{~mm}$ and inner diameter of $240 \mathrm{~mm}$. In addition, the liner is designed to have $5 \mathrm{~mm}$ thickness based on [33].

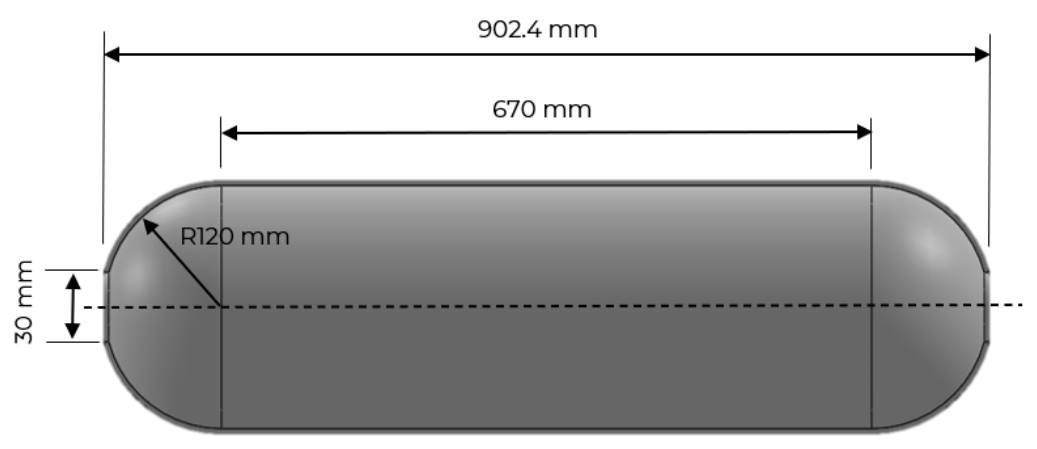

Figure 1. Design of the developed type-IV pressure vessel for liquid ammonia for vehicle. 
In this study, a type-IV pressure vessel for storing ammonia is proposed with the consideration that it is lighter than other pressure vessel types. Several polymer materials that are compatible with ammonia, including high-density polyethylene (HDPE), nylon, polyether ether ketone (PEEK), PET, and PP, are compared initially. PET and PP also have higher temperature resistance compared to HDPE [34,35]. By considering some factors, e.g., ultimate tensile strength, density, and cost, PET and PP are selected as a liner. In addition, CFRP and GFRP are selected as a reinforcement because of their performance and applicability for a type-IV pressure vessel. Figures 2 and 3 show the stress-strain curve of PP and PET, respectively, which are the candidate materials for the tank liner. The detailed properties of PET and PP are listed in Table 2. In addition, the composites used in this study (CFRP and GFRP) have mechanical properties listed in Table 3.

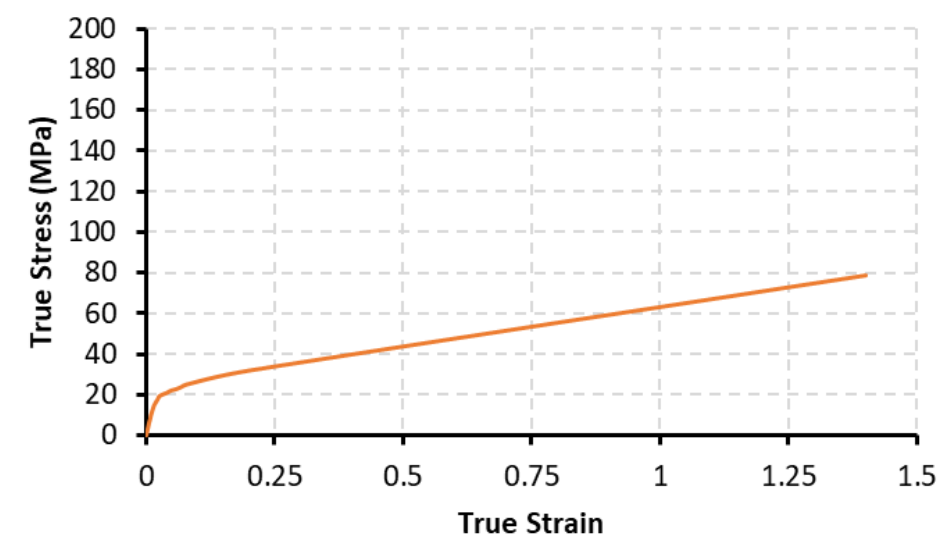

Figure 2. Stress-strain curve of polypropylene (PP) as the candidate material for tank liner [36].

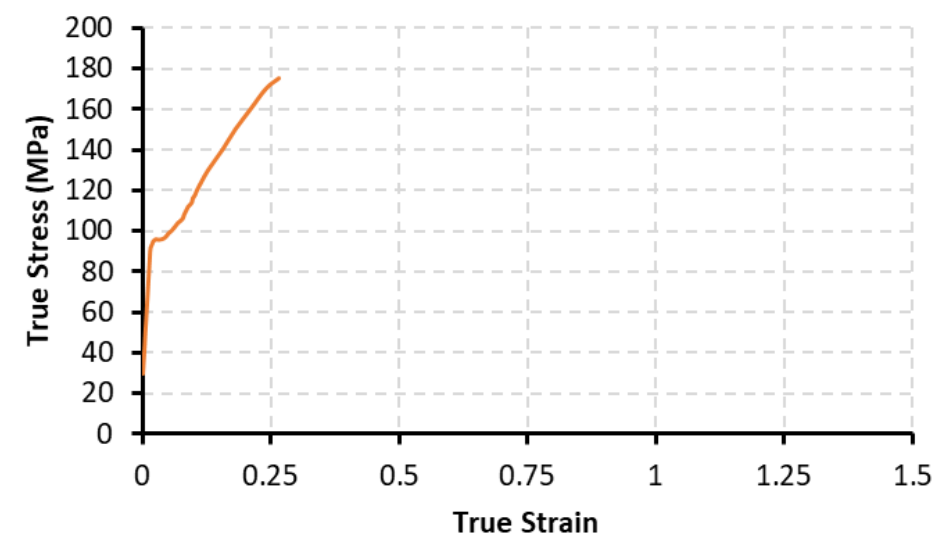

Figure 3. Stress-strain curve of polyethylene terephthalate (PET) as the candidate material for tank liner [37].

Table 2. Properties of PET and PP.

\begin{tabular}{cccc}
\hline Properties & Units & PET & PP \\
\hline Density & $\mathrm{g} / \mathrm{cm}^{3}$ & 1.38 & 0.91 \\
Young modulus & $\mathrm{GPa}$ & 4.348 & 1.150 \\
Yield strength & $\mathrm{MPa}$ & 96.3 & 21 \\
Tensile strength & $\mathrm{MPa}$ & 175 & 79 \\
Poisson's ratio & - & 0.49 & 0.4 \\
\hline
\end{tabular}


Table 3. Properties of carbon-fiber-reinforced polymer (CFRP) and glass-fiber-reinforced polymer (GFRP).

\begin{tabular}{cccc}
\hline Mechanical Properties & Units & CFRP [38] & GFRP [39] \\
\hline Density & $\mathrm{kg} / \mathrm{m}^{3}$ & 1792 & 1970 \\
Longitudinal Young modulus & $\mathrm{GPa}$ & 125.9 & 41.29 \\
Transverse Young modulus & $\mathrm{GPa}$ & 11.3 & 4.21 \\
In-plane shear modulus & $\mathrm{GPa}$ & 5.43 & 3.16 \\
Major Poisson's ratio & - & 0.3 & 0.31 \\
Minor Poisson's ratio & - & 0.42 & 0.42 \\
Longitudinal tensile strength & $\mathrm{MPa}$ & 2000 & 884.5 \\
Longitudinal compressive strength & $\mathrm{MPa}$ & 1100 & 837.17 \\
Transverse tensile strength & $\mathrm{MPa}$ & 80 & 37.38 \\
Transverse compressive strength & $\mathrm{MPa}$ & 280 & 145 \\
Ultimate in-plane shear strength & $\mathrm{MPa}$ & 120 & 44.765 \\
Fiber tensile fracture energy & $\mathrm{kJ} / \mathrm{m}^{2}$ & 91.6 & 28.25 \\
Fiber compressive fracture energy & $\mathrm{kJ} / \mathrm{m}^{2}$ & 79.9 & 80.1 \\
Matrix tensile fracture energy & $\mathrm{kJ} / \mathrm{m}^{2}$ & 0.22 & 0.36 \\
Matrix compressive fracture energy & $\mathrm{kJ} / \mathrm{m}^{2}$ & 1.1 & 7.24 \\
\hline
\end{tabular}

In the practical manufacturing of the tank, initially, the liner is manufactured through injection molding. After the liner is sufficiently inspected for any leakage, the filament winding for the composite is conducted according to the given winding angle. Then, the curing is carried out with the objective of minimizing the degree of polymerization shrinkage of the composite [40]. The process is then continued by sanding for physical finishing and hydrostatic testing to clarify the required specifications of the vessel [41].

In order to be used as a fuel tank in the vehicle, several evaluations are necessary to be carried out to ensure the safety of the pressure vessel. This study focuses on the burst and impact tests conducted by numerical simulation adopting the finite element method. The impact test refers to the regulation No. 67 of the Economic Commission for Europe of the United Nations (UN/ECE), while the burst test refers to the regulation of Federal Motor Vehicle Safety Standards (FMVSS) 304.

\subsubsection{Impact Test (Regulation No. $67 \mathrm{UN} / \mathrm{ECE}$ )}

In order to perform this impact test, the pressure vessel must be filled with a fluid medium, such as a water and glycol mixture, until its weight equals $80 \%$ of liquefied petroleum gas (LPG), which, in this case, is replaced with ammonia having a density of $568.2 \mathrm{~kg} / \mathrm{m}^{3}$. Pressure vessel is projected by the wedge, which is horizontally fixed and parallel to the $x$-axis with a velocity of $50 \mathrm{~km} / \mathrm{h}$.

The wedge should have a length $(L)$ at least equal to the width of the pressure vessel and have an angle of $90^{\circ}$, and the point of impact is rounded with a maximum radius of $2.5 \mathrm{~mm}$. The minimum height $(H)$ of the wedge is $600 \mathrm{~mm}$ [42]. To pass the test procedure, the liner should not exceed its ultimate tensile stress. Figure 4 shows the procedure of the test impact adopted in this study.

\subsubsection{Burst Test (Regulation of FMVSS 304)}

FMVSS 304 consists of three types of tests, which are pressure cycling, hydrostatic burst, and bonfire tests [43]. This research focuses mainly on the burst test in FMVSS 304 to obtain the optimum design. As there are four types of pressure vessel, there are different procedures of burst pressure testing requirements. The type-I pressure vessel is regulated in point 7.2.1, while types II, III, and IV are regulated in point 7.2.2. For a type-I pressure vessel, there should be no leakage when the vessel is subjected to burst pressure. Burst pressure is not less than 2.25 and 3.5 times the service pressure for non-welded and welded pressure vessels, respectively. For pressure vessels types II, III, and IV, there must be no leakage when they are subjected to a burst pressure higher than 2.25 times the service pressure. 

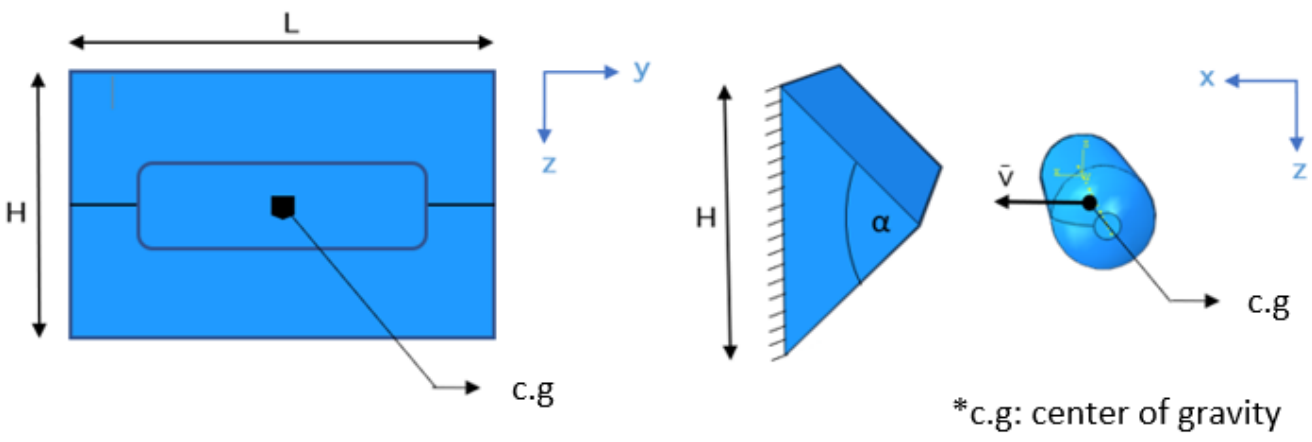

Figure 4. Impact test procedure adopted in this study [37].

\subsection{Optimization Method}

Several models that consist of composite and liner are used with variation of composite layup and several values of winding angle $(\theta)$. The winding axis references are shown in Figure 5 . The model is simulated by the using finite element method to obtain the stress in the liner and composite, and the comparison of each layup to get the optimum composite layup for the model is conducted. For the burst test, a maximum stress in the liner is used as the optimum parameter of the liner, and two composite failure criteria from four failure criteria of Hashin damage initiation criteria is used, which is fiber damage due to tension (highest value of Hashin fiber tension damage initiation criteria, HSNFT) and matrix cracking due to tension damage (highest value of Hashin matrix tension damage initiation criteria, HSNMT). The composite damage caused by tension is used in the burst test as there is no compression load in the liner and composite. A total of 24 composite layers are used as the baseline design in obtaining the lowest liner stress due to burst pressure. In impact test for the composite part, according to the regulation, the damage is allowed in composite part while it is not allowed for the liner part. It is important to note that the interactions between liner-composite and composite-composite are assumed to be perfectly bonded for this research; thus, the failure due to cracking on the interaction is not considered in this study.

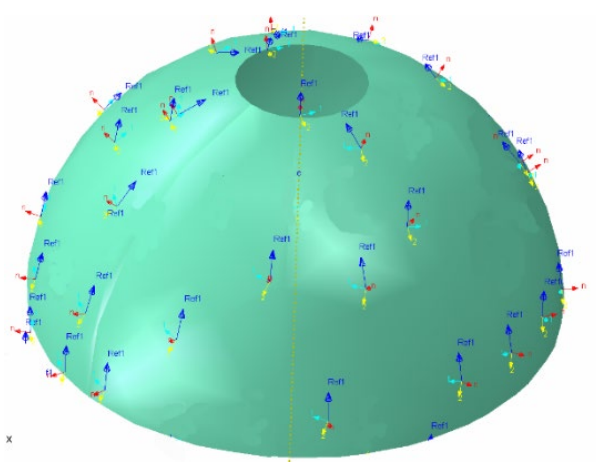

(a)

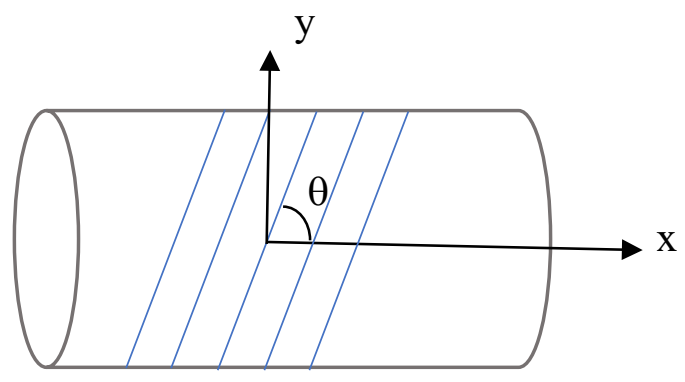

(b)

Figure 5. Filament winding axis reference of pressure vessel: (a) at the dome and (b) at the cylinder body.

\section{Finite Element Method}

The finite element model of the type-IV ammonia pressure vessel is simulated by using the Abaqus 2020 version finite element software (Dassault Systemes, Vélizy-Villacoublay, France) [44]. The model consists of two parts: liner and composite wrapper. An 8-node linear three-dimension solid C3D8R element model is used to discretize the liner and 4 node shell S4R element model is used to discretize the composite wrapper. Moreover, three integration points are used to model the composite. 


\subsection{Material Model}

The liner part is considered isotropic and elastic-plastic, and an isotropic material hardening is adopted into the liner model to simulate the plastic region. Isotropic hardening means that the yield surface changes uniformly in all directions; therefore, the yield stress increases (or decreases) in all stress directions as plastic straining occurs. The isotropic model can be derived by using the stress-strain relation that can be expressed as follows:

$$
\left(\begin{array}{l}
\varepsilon_{11} \\
\varepsilon_{22} \\
\varepsilon_{33} \\
\gamma_{12} \\
\gamma_{13} \\
\gamma_{23}
\end{array}\right)=\left(\begin{array}{cccccc}
1 / E & 1 / E & 1 / E & 0 & 0 & 0 \\
1 / E & 1 / E & 1 / E & 0 & 0 & 0 \\
1 / E & 1 / E & 1 / E & 0 & 0 & 0 \\
0 & 0 & 0 & 1 / G & 0 & 0 \\
0 & 0 & 0 & 0 & 1 / G & 0 \\
0 & 0 & 0 & 0 & 0 & 1 / G
\end{array}\right)\left(\begin{array}{c}
\sigma_{11} \\
\sigma_{22} \\
\sigma_{33} \\
\sigma_{12} \\
\sigma_{13} \\
\sigma_{23}
\end{array}\right),
$$

and

$$
G=\frac{E}{2(1+v)}
$$

where $E$ is the Young's modulus and $v$ is the Poisson ratio. $\sigma_{11}, \sigma_{22}$, and $\sigma_{33}$ are the normal stress in 1 , 2 and 3 directions, respectively. $\sigma_{12}, \sigma_{13}$, and $\sigma_{23}$ are the normal stress in direction 1 of plane normal to direction 2, normal stress in direction 1 of plane normal to direction 3 , and normal stress in direction 2 of plane normal to direction 3 , respectively.

The composite part is considered to be orthotropic elastic. The orthotropic model has the stress-strain relation that can be expressed as:

$$
\left(\begin{array}{c}
\varepsilon_{1} \\
\varepsilon_{2} \\
\gamma_{12}
\end{array}\right)=\left(\begin{array}{ccc}
1 / E_{1} & -v_{12} / E_{1} & 0 \\
-v_{12} / E_{1} & 1 / E_{2} & 0 \\
0 & 0 & 1 / G_{12}
\end{array}\right)\left(\begin{array}{c}
\sigma_{11} \\
\sigma_{22} \\
\tau_{12}
\end{array}\right),
$$

where $E_{1}$ is the Young's modulus along the major axis, $E_{2}$ is the Young's modulus along the minor axis, and $G_{12}$ is the minor direction on the plane of normal direction of major direction. Moreover, $V_{12}$ is the Poisson's ratio of 1-2 plane.

The most general failure criteria used for composite are the Hashin theory. The damage evolution is modeled using fracture energy (Table 3). Hashin damage initiation theory takes into account four possible failure modes in the composite, including (i) fiber breakage due to tension $\left(F_{t}^{t}\right)$, (ii) fiber buckling due to compression $\left(F_{t}^{c}\right)$, (iii) matrix cracking due to tension $\left(F_{m}^{t}\right)$, and (iv) matrix crushing due to compression $\left(F_{m}^{c}\right)$. The damage initiation criteria have the following general forms:

$$
\begin{gathered}
F_{f}^{t}=\left(\frac{\hat{\sigma}_{11}}{X^{T}}\right)^{2} \text { for } \sigma_{11}>0, \\
F_{f}^{c}=\left(\frac{\hat{\sigma}_{11}}{X^{C}}\right)^{2} \text { for } \sigma_{11}<0, \\
F_{m}^{t}=\left(\frac{\hat{\sigma}_{22}}{Y^{T}}\right)^{2}+\left(\frac{\hat{\tau}_{12}}{S^{L}}\right)^{2} \text { for } \sigma_{22}>0, \\
F_{m}^{c}=\left(\frac{\hat{\sigma}_{22}}{2 S^{T}}\right)^{2}+\left[\left(\frac{\hat{\tau}_{12}}{S^{L}}\right)^{2}-1\right] \frac{\hat{\sigma}_{22}}{Y^{c}}+\left(\frac{\hat{\tau}_{12}}{S^{L}}\right)^{2} \text { for } \sigma_{22}<0,
\end{gathered}
$$

where $X^{T}$ is the tensile strength in the fiber direction, $X^{c}$ is the compressive strength in the fiber direction, $Y^{T}$ is the tensile strength perpendicular to the fibers, and $Y^{c}$ is the compressive strength perpendicular to the fibers. $S^{L}$ is the longitudinal shear strength and $S^{T}$ is the transverse shear strength. $\sigma_{11}$ and $\sigma_{22}$ are the normal stress in 1 and 2 directions, respectively. $\tau_{12}$ is the shear stress that occurred 
in the element. Each of the failure mode in Hashin damage initiation theory has the same value, which is 1 . If one of the index values surpasses the value of 1 , the damage initiation theory is met.

Abaqus finite element software has the ability to implement Hashin damage initiation and the post-damage initiation behavior or damage evolution. It implements the energy dissipation of each failure mode. The stress-strain state of a damage composite has the form of

$$
\sigma=C_{d} \varepsilon
$$

$$
C_{d}=\frac{1}{D}\left[\begin{array}{ccc}
\left(1-d_{f}\right) E_{1} & \left(1-d_{f}\right)\left(1-d_{m}\right) v_{21} E_{1} & 0 \\
\left(1-d_{f}\right)\left(1-d_{m}\right) v_{12} E_{2} & \left(1-d_{m}\right) E_{2} & 0 \\
0 & 0 & \left(1-d_{s}\right) G D
\end{array}\right]
$$

where $D=1-\left(1-d_{f}\right)\left(1-d_{m}\right) v_{12} v_{21}, d_{f}$ is the current state of fiber damage, $d_{m}$ is the current state of matrix damage, and $d_{s}$ is the current state of shear damage. Moreover, $d_{f}, d_{m}$ and $d_{s}$ are derived from the Hashin damage, calculated as follows:

$$
\begin{gathered}
d_{f}=\left\{\begin{array}{ll}
d_{f}^{t} & \text { if } \hat{\sigma}_{11} \geq 0 \\
d_{f}^{t} & \text { if } \hat{\sigma}_{11}<0
\end{array},\right. \\
d_{m}=\left\{\begin{array}{ll}
d_{m}^{t} & \text { if } \hat{\sigma}_{22} \geq 0 \\
d_{m}^{c} & \text { if } \hat{\sigma}_{22}<0
\end{array},\right. \\
d_{s}=1-\left(1-d_{f}^{t}\right)\left(1-d_{f}^{c}\right)\left(1-d_{m}^{t}\right)\left(1-d_{m}^{c}\right), \\
d=\frac{\delta_{e q}^{f}\left(\delta_{e q}-\delta_{e q}^{f}\right)}{\delta_{e q}\left(\delta_{e q}^{f}-\delta_{e q}^{0}\right)},
\end{gathered}
$$

where $\delta_{e q}^{f}$ is the equivalent displacement when the stress reaches zero in the stress-displacement and is a function of fracture energy. In addition, $\delta_{e q}^{0}$ is the equivalent displacement when the damage initiates. It occurs when one of the damage initiation modes of Hashin damage criteria equals 1 . Moreover, $\delta_{e q}$ is the equivalent displacement at a given applied strain.

\subsection{Simulation Details}

The vessel is basically overwrapped with 24 plies of composite. This ply number of composite is used because it is the least common multiple of composite stacking sequences used in this research. Each composite ply has a thickness of $0.4 \mathrm{~mm}$, resulting in the total composite thickness of $9.6 \mathrm{~mm}$. Considering both liner and composite thicknesses, the total (outer) diameter of this pressure vessel is $269.2 \mathrm{~mm}$. There are several ways to model the composite skin in the finite element software with the filament winding manufacturing method. Gentilleau et al. [45] modeled the composite part by using built-in Wound Composite Modeler (WCM) that is able to model the composite with advanced composite thickness based on the location. The method is considered applicable to model the composite at the dome section. Major damage in the pressure vessel occurs at the middle section of the pressure vessel, while minor damage occurs at the dome section. $\mathrm{Zu}$ et al. [46] used mandrel profile updates on a pressure vessel to model the composite. However, this requires advanced equipment and converter because it requires the manufactured pressure vessel to be scanned and modeled into the finite element software. In this research, the composite skin is assumed to have homogenous thickness at all section of pressure vessel as the failure in the pressure vessel is projected to happen in the middle section of the pressure vessel, which is in agreement with the research conducted by Gentilleau et al [45].

The interaction between liner and composite material is assumed to be perfectly bonded, hence tied contact is used in Abaqus. The meshing used for burst and impact tests is different due to the convergence needed for each case. For both impact and burst tests, five points are used to discretize 
the solid element in the thickness direction. However, the meshing and total elements used for each case are different due to the convergence needed for each case. For the burst test, the convergence is achieved with 89,550 and 17,800 elements for liner and composite parts, respectively. On the other hand, for the impact test, the total elements needed to achieve its convergence is 293,000 elements. The meshing result for burst test is shown in Figure 6.

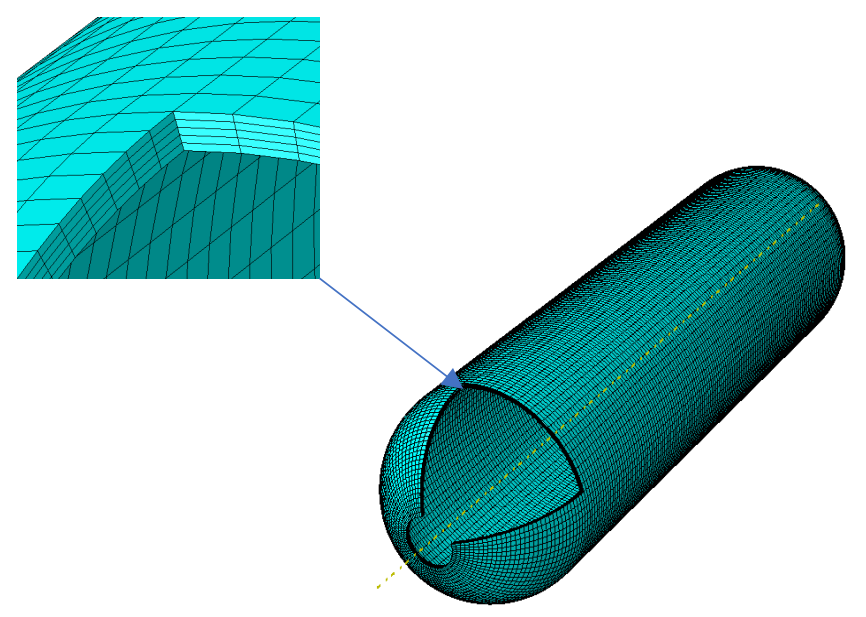

Figure 6. Model meshing for burst pressure test.

The burst test is simulated with a static, general procedure with a burst pressure of $6.5 \mathrm{MPa}$ based on the used regulation. The surface to which the burst pressure load is applied is the inner surface of the liner part. For the boundary condition, fixed and symmetry boundary conditions are used to ensure that the simulation has been conducted according to the procedure. The developed model which consist of load application and boundary conditions is shown in Figure 7. Furthermore, for the impact test case, a quad-structured meshing type has been selected, and is not constant for the whole part. In order to reduce the simulation time, the impacted region has the finer mesh, as shown in Figure 8.

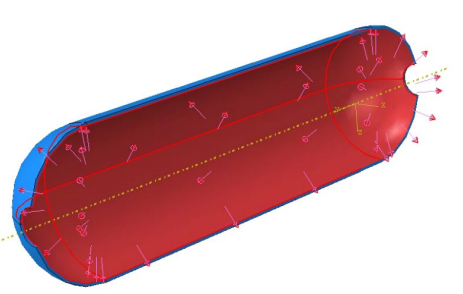

(a)

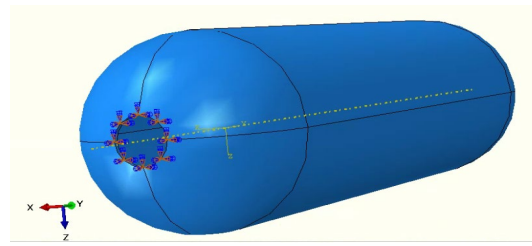

(b)

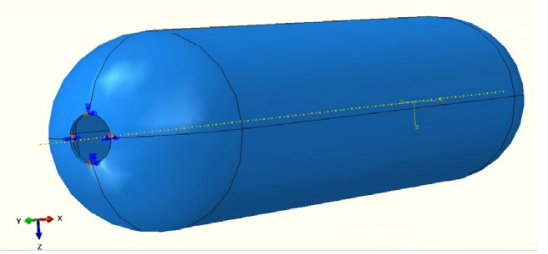

(c)

Figure 7. Developed model for burst pressure test: (a) pressure load surface, (b) fixed boundary condition on one end, and (c) symmetry boundary condition on the other end. 


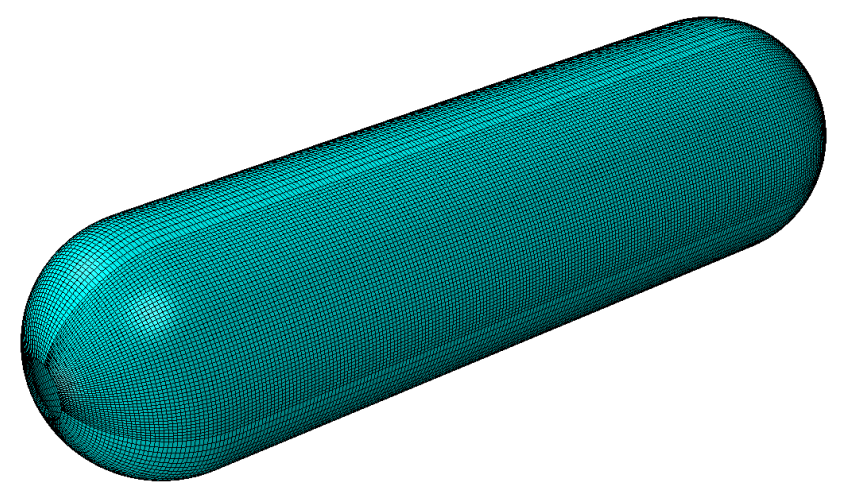

Figure 8. Finite element model of pressure vessel for impact case.

Figure 9 shows how the impact test is modeled in Abaqus software. The pressure vessel is given a velocity of $13.8 \mathrm{~m} / \mathrm{s}$, and the wedge is fixed at the reference point. Dynamic Explicit is selected as a procedure to simulate this impact test.

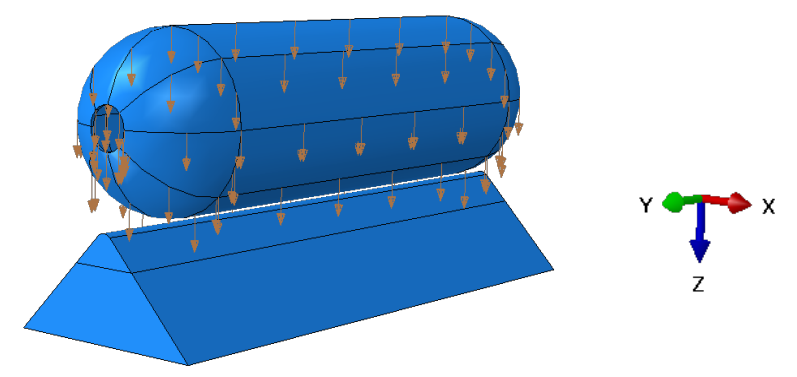

Figure 9. Developed model for the impact test.

\section{Results and Discussion}

\subsection{Burst Test}

\subsubsection{Stress Distribution}

Figure 9 shows the simulation results of vessels composed of PET-GFRP that have a laminate stacking sequence of $[ \pm \theta]_{6 s}$. Two values of $\theta$ are selected; they are $10^{\circ}$ and $70^{\circ}$ that represent the $\theta$ close to $0^{\circ}$ and $90^{\circ}$, respectively. In $\theta=10^{\circ}$, the displacement happens mainly in the radial direction of the pressure vessel, and, in $\theta=70^{\circ}$, the displacement occurs in the longitudinal direction. Table 4 shows the comparisons of stress distribution and displacement for both conditions. Both selected cases have the same stress distribution, with maximum von Mises stress happening at the middle section of the pressure vessel. However, the maximum stress of $\theta=70^{\circ}$ shows a much lower maximum stress generated in the pressure vessel compared to $\theta=10^{\circ}$. This result gives an overview of stress generated on the pressure vessel. For the Hashin failure criteria, the maxima for every stacking sequence has the same tendency with the selected cases; thus, it can be concluded that the maximum stress is generated at the cylindrical part of the pressure vessel, and not at the dome part. 
Table 4. Stress distribution and displacement of selected simulated cases $\left([ \pm 10]_{6 \mathrm{~s}}\right.$ and $\left.[ \pm 70]_{6 \mathrm{~s}}\right)$.

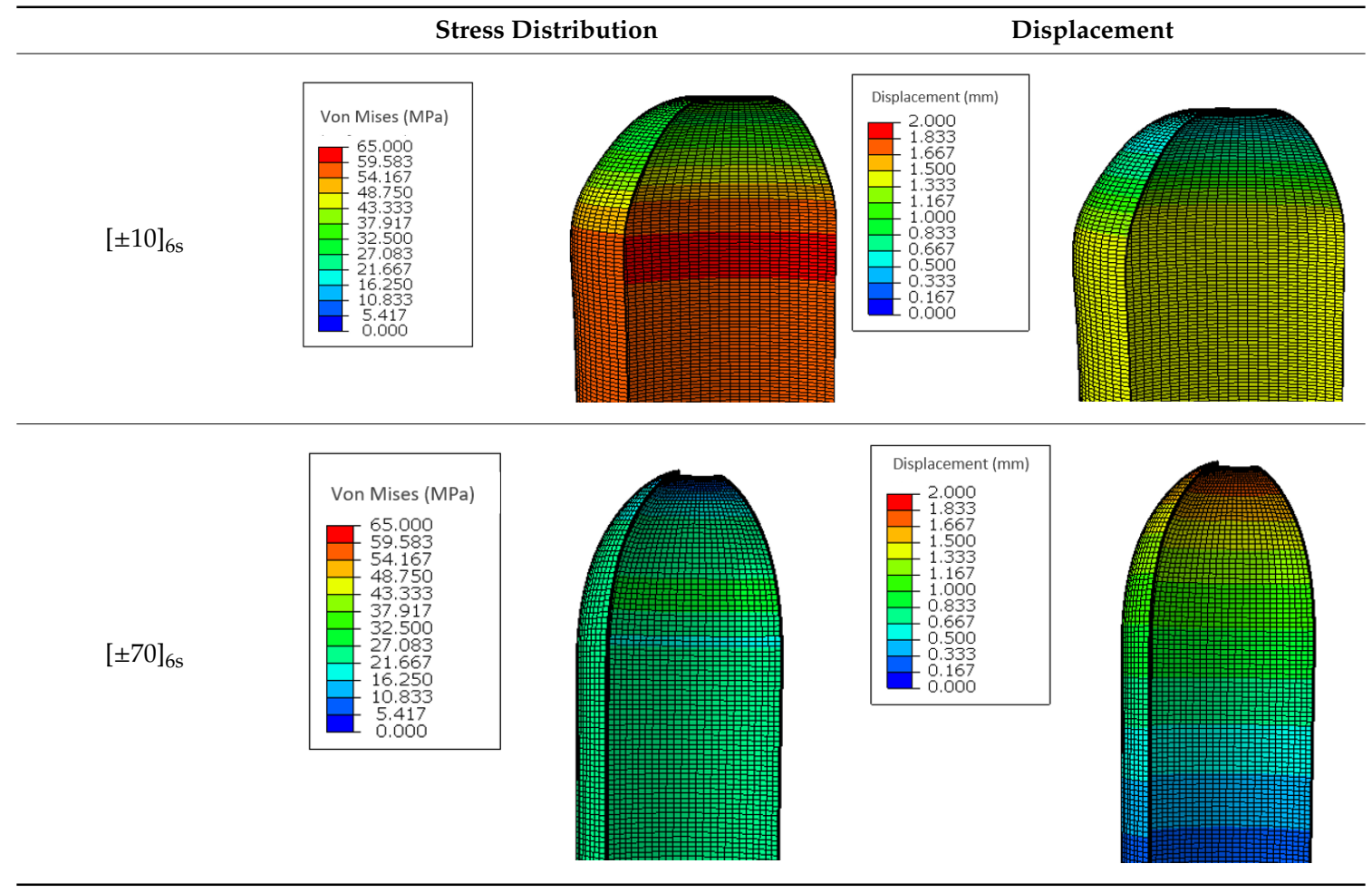

\subsubsection{Laminate Stacking Sequence of $[ \pm \theta]_{6 \mathrm{~s}}$}

Figure 10 shows the calculation results for the laminate stacking sequence of $[ \pm \theta]_{6 \mathrm{~s}}$ when $\theta$ is varied from $10^{\circ}$ to $90^{\circ}$. Specifically, Figure 10a shows the maximum stress in the liner of pressure vessel. It is shown that the PP-CFRP vessel has the lowest maximum stress in the liner. Meanwhile, PET-CFRP generates the highest maximum stress in the liner. It is important to note that PET-based vessels tend to experience higher maximum stress in its liner compared to PP-based vessels since the PET has a higher elastic modulus, yield strength, and plastic strain hardening. This also results in lower stresses in the composite skin of the vessels with PET liner. In addition, the optimum stacking sequence for generating low maximum stresses in the liner can be achieved when the winding angle of the composite skin is about $50^{\circ}$ for both CFRP- and GFRP-based vessels.

Figure 10b,c also indicate that GFRP-based pressure vessels have higher stresses compared to its allowable values, i.e., HSNFT and HSNMT. For all evaluated cases, HSNFT values are lower than 1, meaning that the fiber damage does not occur. In addition, GFRP-based vessels generally develop matrix tension cracking (i.e., HSNMT $>1$ ), while no matrix tension damage is observed for CFRP-based vessels for various values of $\theta$. It is also shown that the higher value of HSNFT gives lower stress in the liner since composite has a higher stiffness in the liner direction compared to the matrix.

\subsubsection{Laminate Stacking Sequence of $[0 / \pm \theta]_{4 \mathrm{~s}}$}

The calculation results for the laminate stacking sequence of $[0 / \pm \theta]_{4 \mathrm{~s}}$ for each corresponding value of $\theta$ are shown in Figure 11. Figure 11a represents the maximum stress in the liner. The optimum layup can be found when $\theta$ is $90^{\circ}$, i.e., when the laminate stacking sequence is $[0 / \pm 90]_{4 s}$. On the other hand, the worst performance is found when $\theta$ is in the range from 10 to $30^{\circ}$. This is because the stress field is mainly in the helical direction and is withheld mostly by the matrix instead of the fiber. It is also shown that PET-based vessels tend to experience higher maximum stress in its liner compared to PP-based vessels. This is due to the phenomenon that PET has a higher elastic modulus, higher yield strength and higher plastic strain hardening. Higher maximum stress in the liner occurs following the increase in HSNMT. 


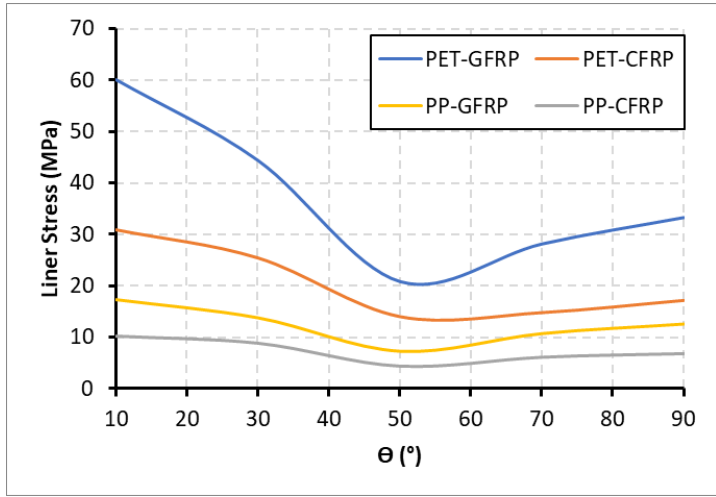

(a)

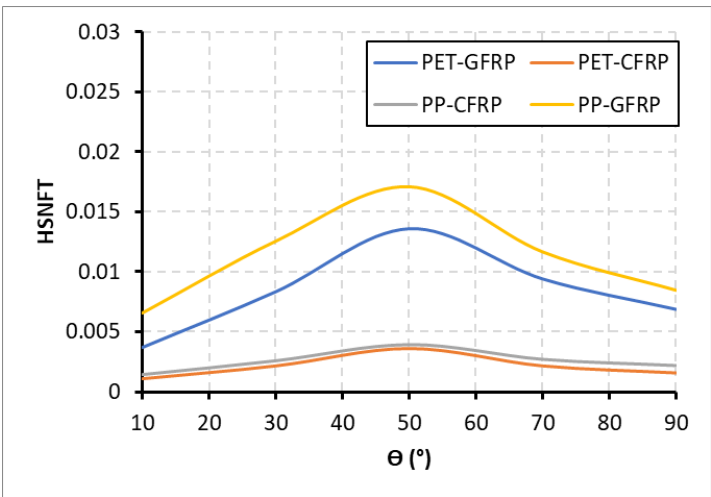

(b)

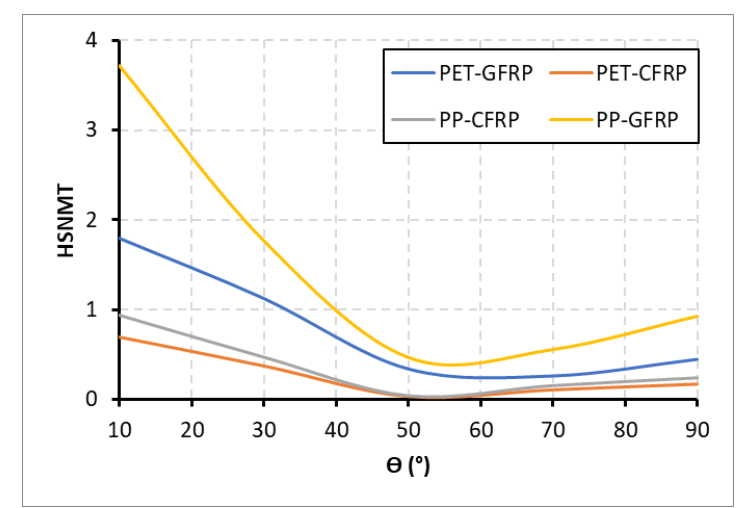

(c)

Figure 10. Calculation results for the laminate stacking sequence of $[ \pm \theta]_{6 \mathrm{~s}}$ for various values of $\theta$ : (a) the maximum stress in the liner, (b) Hashin fiber tension damage initiation criteria (HSNFT), and (c) Hashin matrix tension damage initiation criteria (HSNMT).

Figure 11b,d show that HSNFT values are lower than 1, indicating that fiber damage does not occur for all four cases. Meanwhile, Figure 11c,e also indicate that the GFRP-based pressure vessel experiences higher stress compared to its allowable values (i.e., HSNMT > 1) for $\theta$ lower than about $40^{\circ}$ for PET and about $50^{\circ}$ for PP. On the other hand, GFRP-based pressure vessels exhibit no failure on fiber for all evaluated values of $\theta$.

\subsubsection{Laminate Stacking Sequence of $[90 / \pm \theta]_{4 \mathrm{~s}}$}

Figure 12 shows the calculation results for the laminate stacking sequence of $[90 / \pm \theta]_{4 \mathrm{~s}}$ where $\theta$ is varied from $0^{\circ}$ to $80^{\circ}$. $\theta$ of $90^{\circ}$ is not simulated, as it is similar to the stacking sequence of $[ \pm 90]_{6 s}$. Figure 12a represents the maximum stress in the liner of pressure vessels. It is shown that the optimum stacking sequence for generating low maximum stress in the liner can be achieved with the stacking sequence ranges between $[90 / \pm 40]_{4 \mathrm{~s}}$ and $[90 / \pm 50]_{4 \mathrm{~s}}$ for GFRP and between $\left[90 / \pm 30^{\circ}\right]_{4 \mathrm{~s}}$ and $\left[90 / \pm 40^{\circ}\right]_{4 \mathrm{~s}}$ for CFRP. The performance is getting worse when $\theta$ is larger than $50^{\circ}$, and the worst one is obtained when $\theta$ is approaching $90^{\circ}$. This is because the stress field in longitudinal direction is mainly withheld by the matrix instead of the fiber. It is also important to note that PP-based vessels experience lower stress in the liner compared to PET-based vessels. 


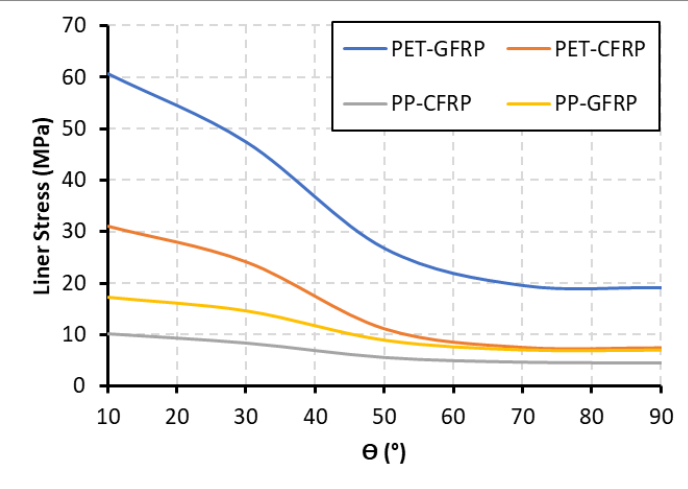

(a)

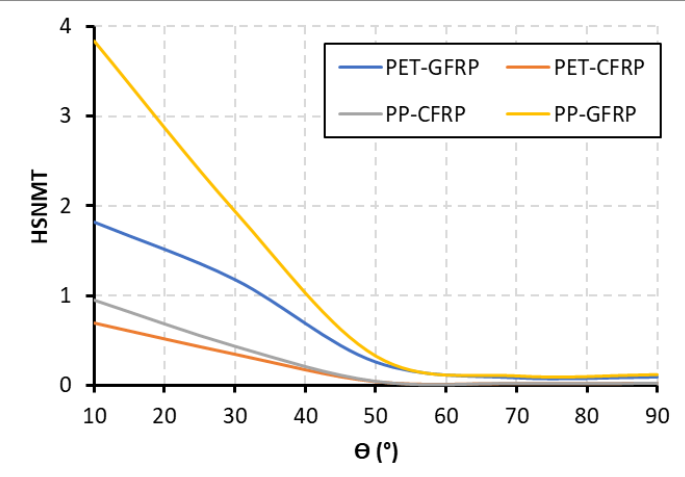

(c)

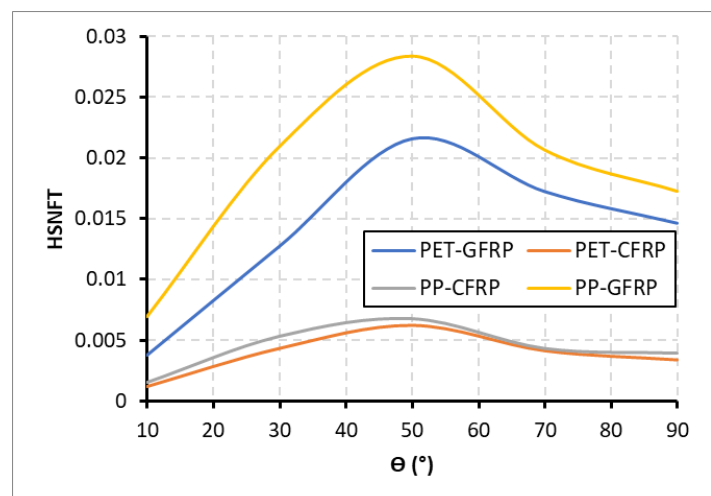

(b)

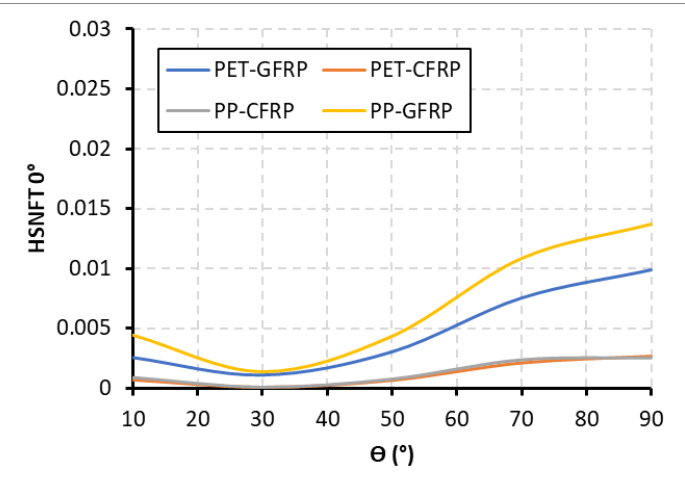

(d)

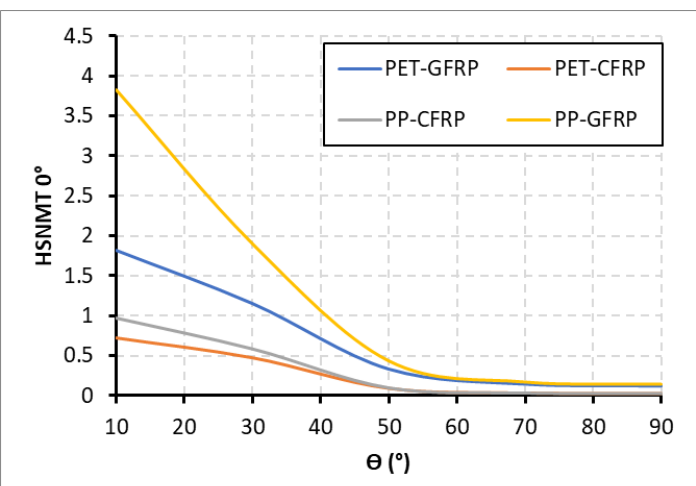

(e)

Figure 11. Calculation results for the laminate stacking sequence of $[0 / \pm \theta]_{4 \mathrm{~s}}$ for various values of $\theta$ : (a) the maximum stress in the liner, (b) HSNFT, (c) HSNMT, (d) HSNFT of $0^{\circ}$ composites, and (e) HSNMT of $0^{\circ}$ composites.

From Figure 12b,d, HSNFT has a value lower than 1, meaning that there is no fiber damage in all the evaluated cases. CFRP-based vessels have a lower HSNFT value and liner stress compared to GFRP-based vessels. Moreover, Figure 12c,e also indicate that no matrix failure occurs for all four combination cases as no HSNMT value is larger than 1.

4.1.5. Laminate Stacking Sequence of $[90 / \pm \theta / 90]_{3 \mathrm{~s}}$

The results of calculation for the laminate stacking sequence of $[90 / \pm \theta / 90]_{3 \mathrm{~s}}$ for various values of $\theta$ ranging from $10^{\circ}$ to $80^{\circ}$ are shown in Figure $13 . \theta$ of $90^{\circ}$ is not simulated as it is similar to the 
stacking sequence of $[ \pm 90]_{6 s}$. Furthermore, Figure 13a shows the maximum stress in the liner It is shown that the optimum fiber winding angle to obtain the low maximal stress on fiber is ranging between $[90 / \pm 20 / 90]$ and $[90 / \pm 30 / 90]$ for all four combination cases. For $\theta$ close to $90^{\circ}$, the stress liner reaches the highest value because there is no fiber that withholds the stress in the longitudinal direction. It is also shown that PET-based vessels have higher maximum stress compared to PP-based vessels due to higher elastic modulus, yield strength, and plastic strain hardening properties of PET compared to PP. This also results in lower stress experienced by the composite skin of PET-based vessels.

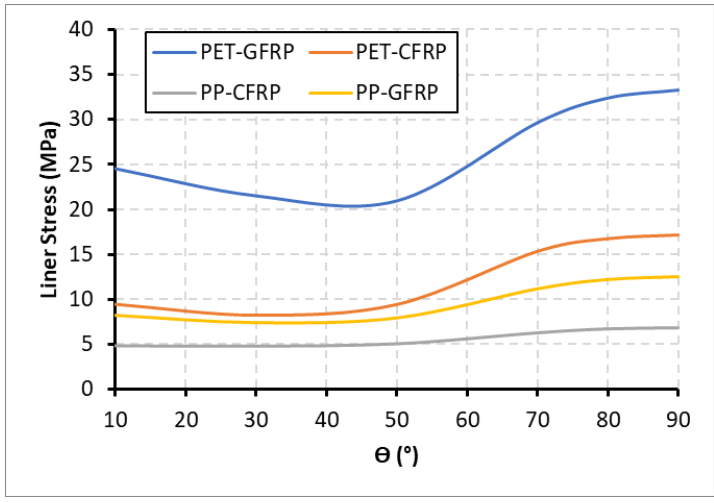

(a)

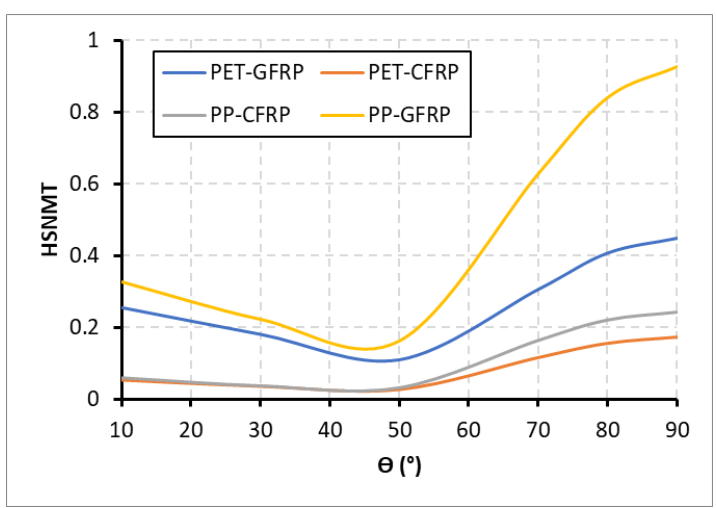

(c)

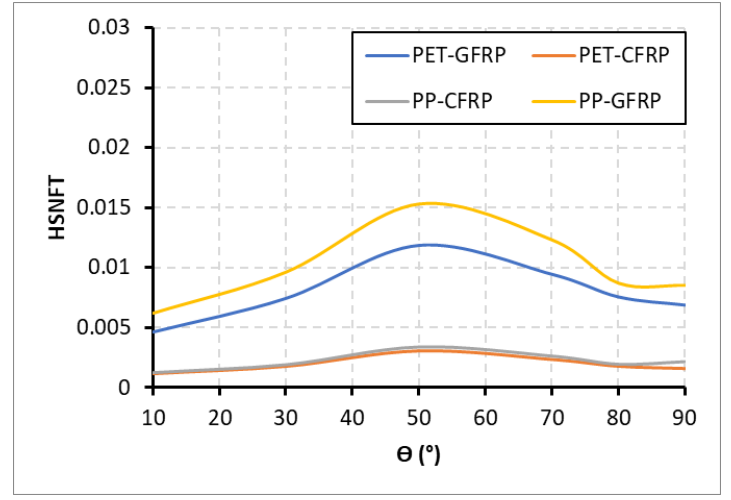

(b)

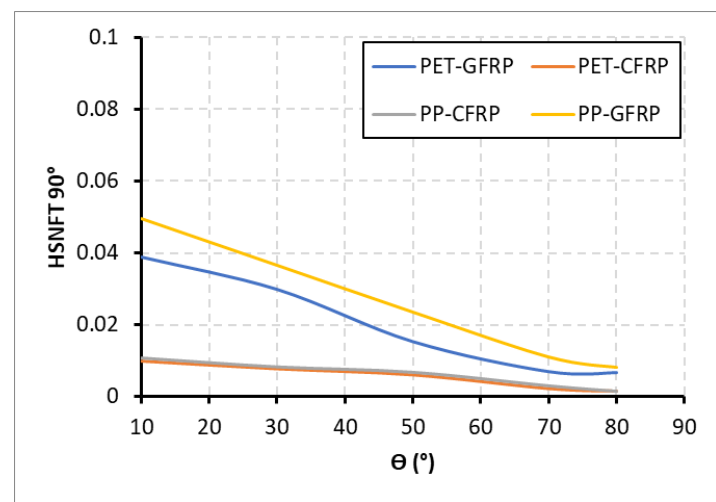

(d)

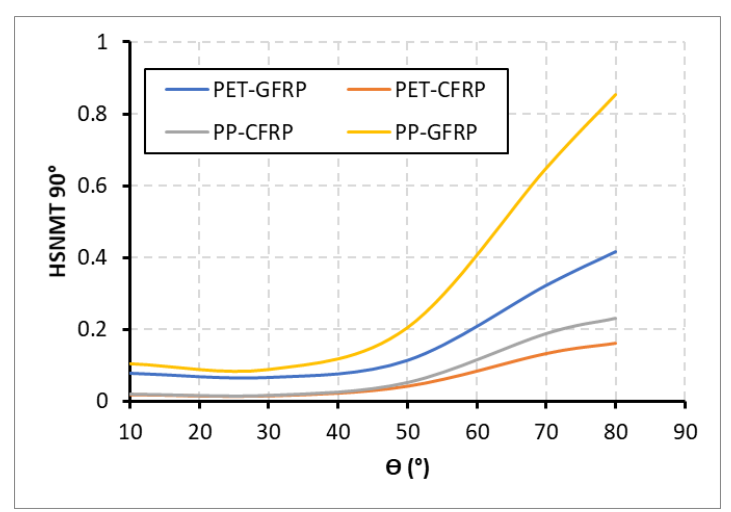

(e)

Figure 12. Calculation results for the laminate stacking sequence of $[90 / \pm \theta]_{4 \mathrm{~s}}$ for various values of $\theta$ : (a) the maximum stress in the liner, (b) HSNFT, (c) HSNMT, (d) HSNFT for the composite layer with a winding angle of $90^{\circ}$, and (e) HSNMT for the composite layer with a winding angle of $0^{\circ}$. 


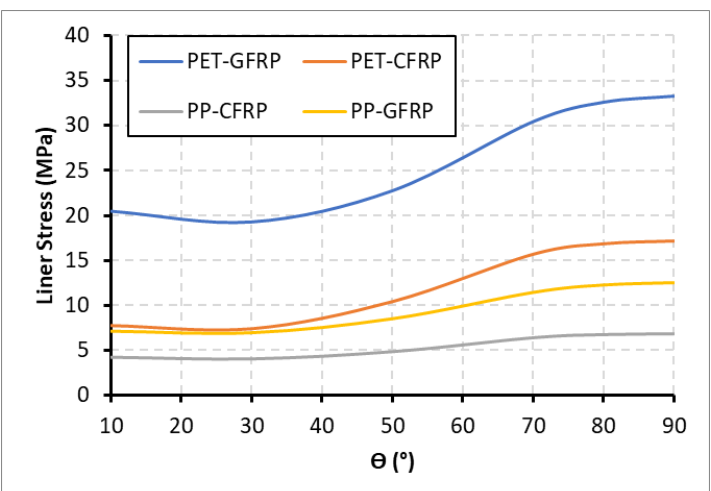

(a)

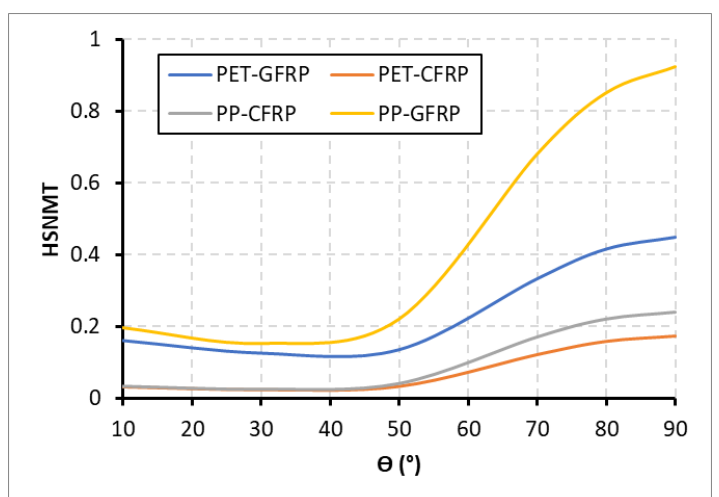

(c)

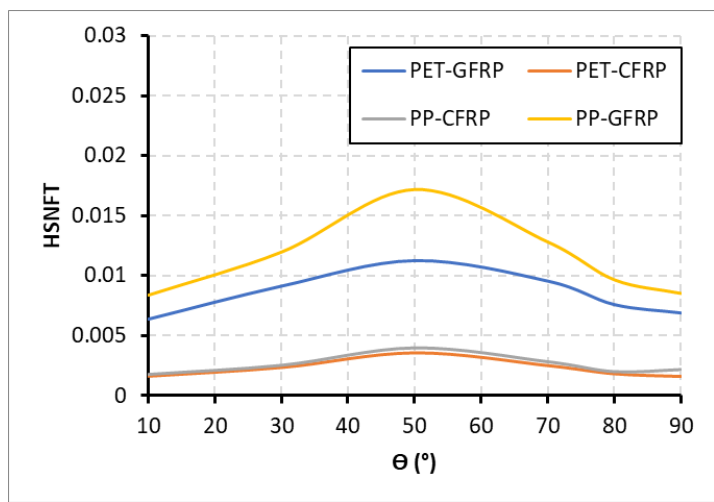

(b)

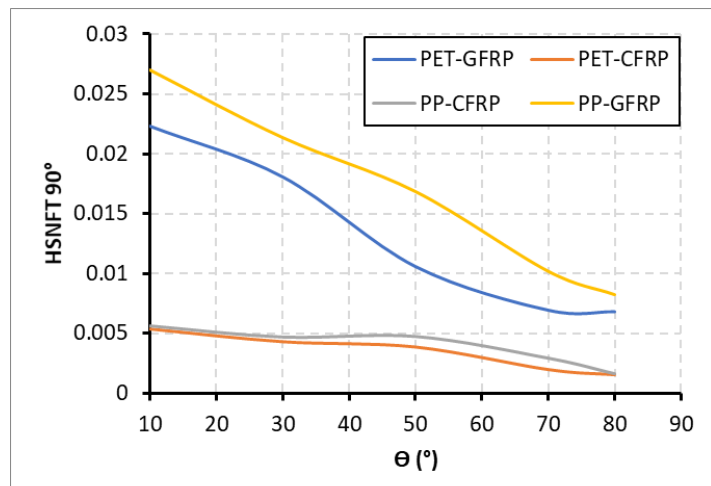

(d)

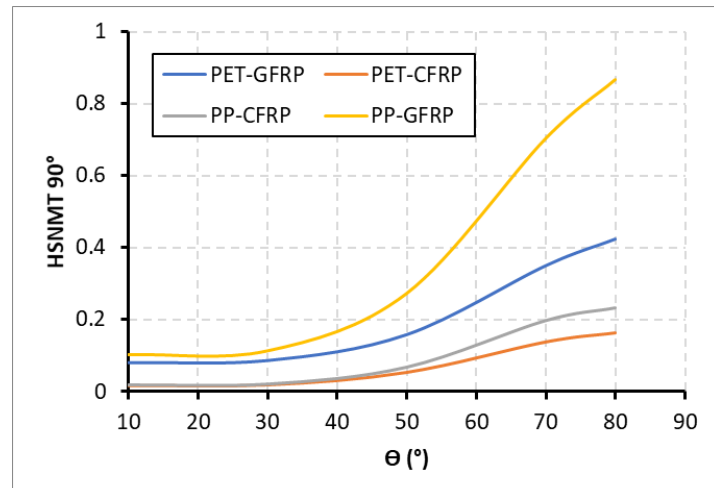

(e)

Figure 13. Calculation results for the laminate stacking sequence of $[90 / \pm \theta / 90]_{3 \mathrm{~s}}$ for various values of $\theta$ : (a) the maximum stress in the liner, (b) HSNFT, (c) HSNMT, (d) HSNFT for the composite layer with a winding angle of $0^{\circ}$, and (e) HSNMT for the composite layer with a winding angle of $0^{\circ}$.

Figure $13 \mathrm{~b}$,d show that there is no fiber failure occurred in all evaluated cases (i.e., HSNFT $<1$ ). In addition, GFRP-based vessels have a lower ability to withstand the load, while they contribute in higher stress experienced by the liner compared to CFRP. Moreover, Figure 13c,e show that the matrix failure does not occur in all four combination cases (HSNMT $<1$ ). It also can be concluded that the higher load received by the matrix results in higher stress in the liner. The results of stacking sequence of $[90 / \pm \theta / 90]_{3 s}$ are quite similar to ones with stacking sequence of $[90 / \pm \theta]_{4 s}$. 
4.1.6. Laminate Stacking Sequence of $[0 / \pm \theta / 90]_{3 \mathrm{~s}}$

Figure 14 shows the calculation results for the laminate stacking sequence of $[0 / \pm \theta / 90]_{3 s}$ for various values of $\theta$. Moreover, Figure 14a represents the maximum stress in the liner. The optimum stacking sequence to obtain a low maximum stress in the liner is the same for all four cases, which is around $[0 / \pm 70 / 90]$. PET has the higher elastic modulus, yield strength, and plastic strain hardening compared to PP. Therefore, the PET-based vessel tends to have higher stress in the liner. It also results in lower stress in the composite skin.

Figure 14b,d,f indicate that HSNFT values for all evaluated cases are lower than 1, meaning that there is no fiber damage. Moreover, Figure 14c,e,g show that HSNMT values for all evaluated cases are also lower than 1 , which means that there is no matrix tension damage. GFRP-based vessels have higher values of HSNFT and HSNMT compared to CFRP-based vessels.

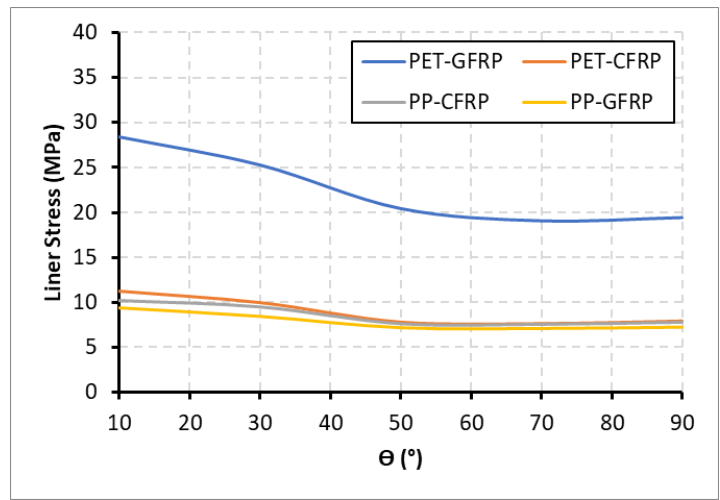

(a)

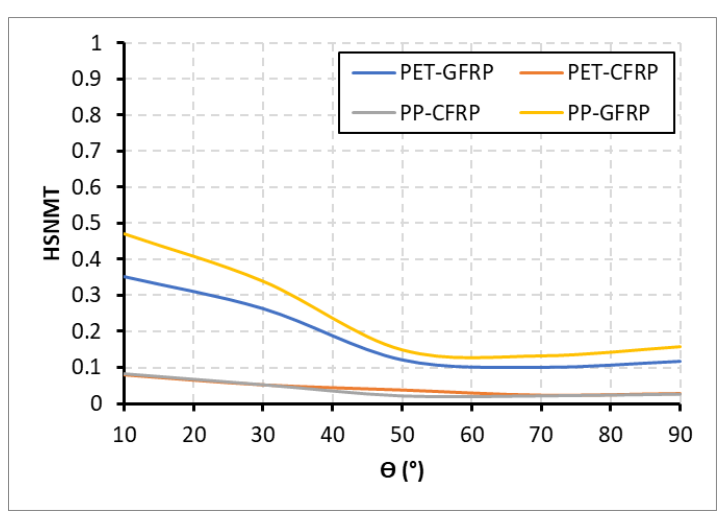

(c)

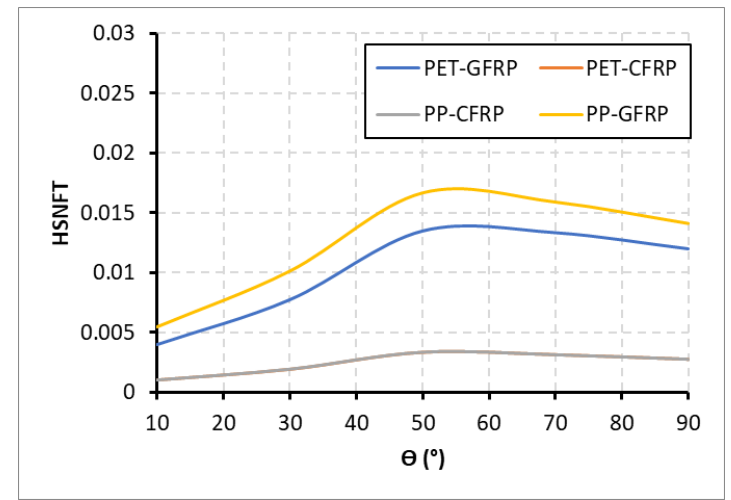

(b)

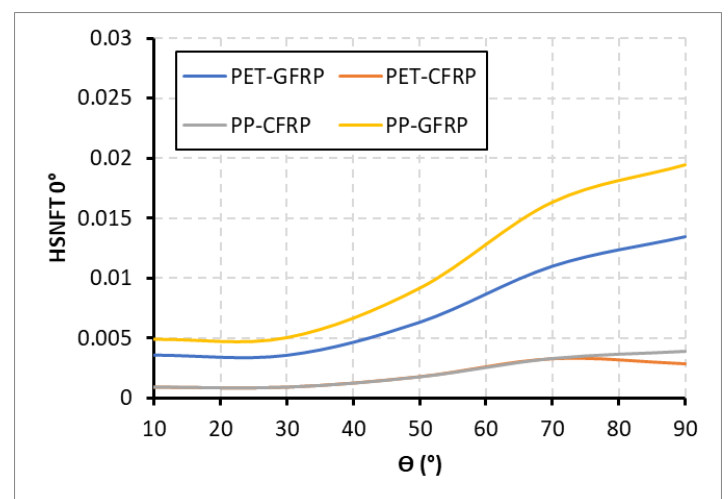

(d)

Figure 14. Cont. 


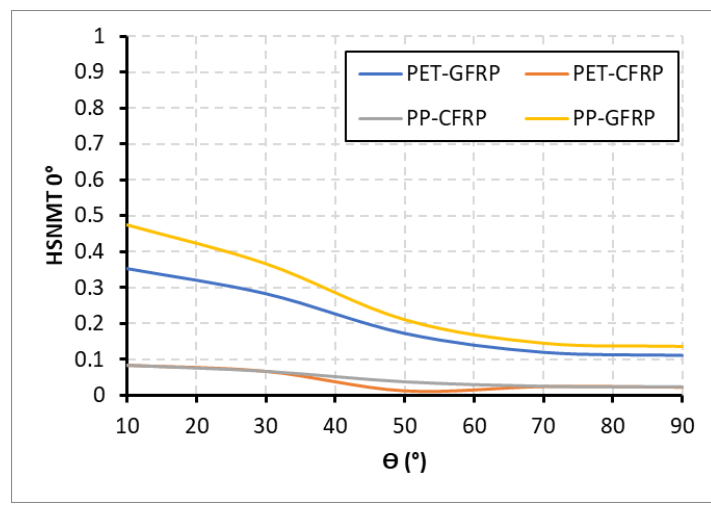

(e)

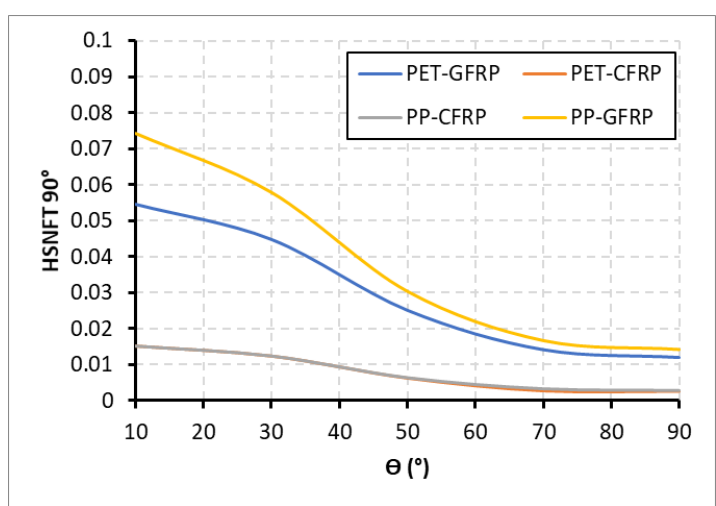

(f)

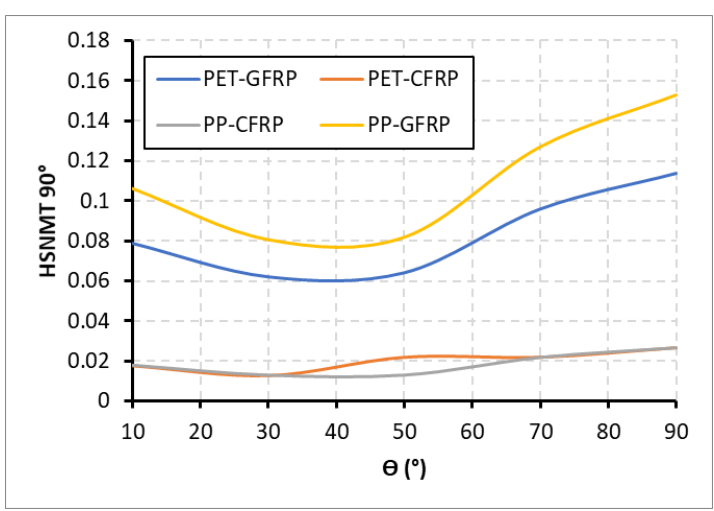

$(\mathrm{g})$

Figure 14. Calculation results for the laminate stacking sequence of $[0 / \pm \theta / 90]_{3 s}$ for various values of $\theta$ : (a) the maximum stress in the liner, (b) HSNFT, (c) HSNMT, (d) HSNFT for the composite layer with a winding angle of $0^{\circ}$, (e) HSNMT for the composite layer with a winding angle of $0^{\circ}$, (f) HSNFT for the composite layer with a winding angle of $90^{\circ}$, and (g) HSNMT for the composite layer with a winding angle of $90^{\circ}$.

\subsubsection{Comparison between Stacking-Sequences}

It is shown that all the combinations have a similar tendency for each stacking sequence. Utilizing PET as liner material results in higher stress for every layup and lower safety factor of liner compared to the material's ultimate strength than using PP as liner material. In addition, utilizing CFRP gives lower stress, resulting in lower thickness needed on pressure vessel design. The lowest maximum liner stresses of vessels with compositions of PET-GFRP, PET-CFRP, PP-CFRP, and PP-GFRP can be achieved at the stacking sequences of $[0 / \pm 70 / 90]_{3 s},[0 / \pm 90]_{4 s},[90 / \pm 30 / 90]_{3 s}$, and $[0 / \pm 90]_{4 s}$, respectively, with the values of $19.11,7.363,4.012$, and $6.962 \mathrm{MPa}$. Hence, the lowest maximum stress in the liner during the burst test can be achieved by the pressure vessel with PP-CFRP composition and stacking sequence of $[90 / \pm 30 / 90]_{3 s}$. It is important to note that from manufacturing point of view, winding angle of $0^{\circ}$ is technically difficult to manufacture the middle section of pressure vessel. Furthermore, both winding angles of $0^{\circ}$ and $90^{\circ}$ are difficult in manufacturing the dome section. The simulation with winding angles of $0^{\circ}$ and $90^{\circ}$ is only conducted for theoretical study.

For all evaluated cases, the stress occurs at the PET and PP liner is still significantly lower than its ultimate strength, only reaching $40 \%$ of its yield strength. As the PET and PP properties are temperature dependent, it is important to measure the percentage of the stress generated to its yield strength. Based on the research conducted by Ariyama et al. [47], the tensile strength of polymer decreased by $20 \%$ at 
temperature of $50{ }^{\circ} \mathrm{C}$. Therefore, by assuming that the tensile strength decreased by $20 \%$ due to the increase in temperature, the stress generated on the liner is considered safe.

\subsection{Impact Test}

\subsubsection{Effect of Stacking Sequence on the Liner}

Figure 15 shows the von Mises maximum stress in the liner with various stacking sequences of $[90 / \pm \theta]_{4 s},[ \pm \theta]_{6 s},[90 / \pm \theta / 90]_{3 s},[0 / \pm \theta]_{4 s}$, and $[0 / \pm \theta / 90]_{3 s}$. It is shown that all the material combinations have a similar tendency for each stacking sequence. The maximum stress in the liner tends to decrease when the $\theta$ approaches $90^{\circ}$. At that point, the maximum stress in liner reaches the minimum value. The maximum stress location can be seen in Figure 16. All of those stacking sequences with an extreme degree of $0^{\circ}$ and $90^{\circ}$ are not realistic to be adopted practically. It must be understood that these results are included in this investigation as a theoretical domain.

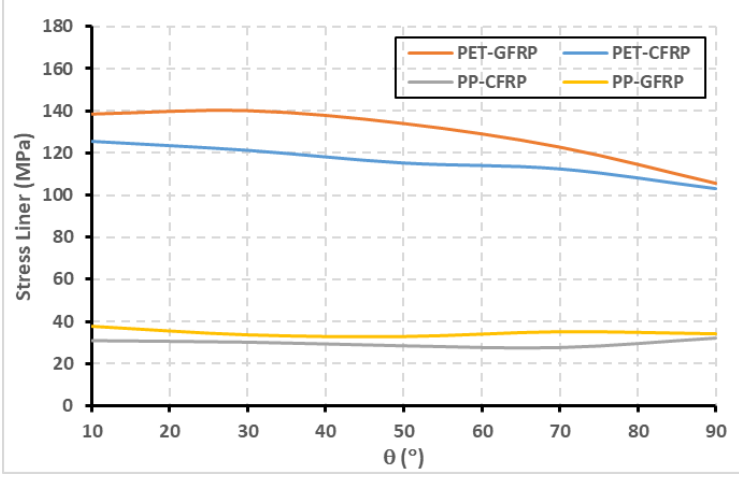

(a)

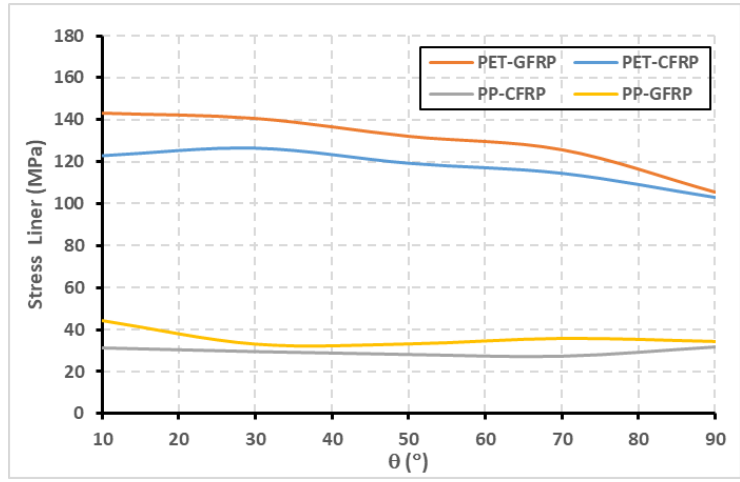

(c)

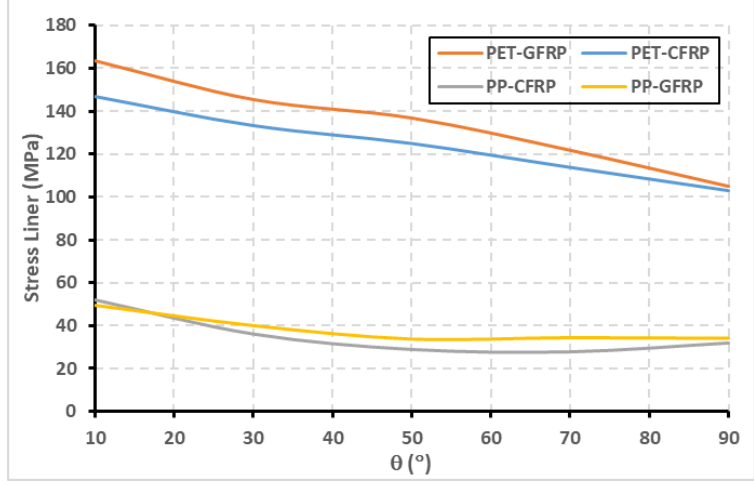

(b)

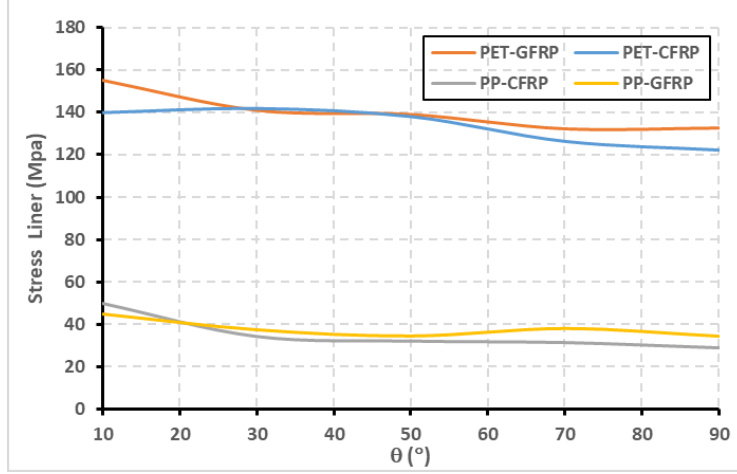

(d)

Figure 15. Cont. 


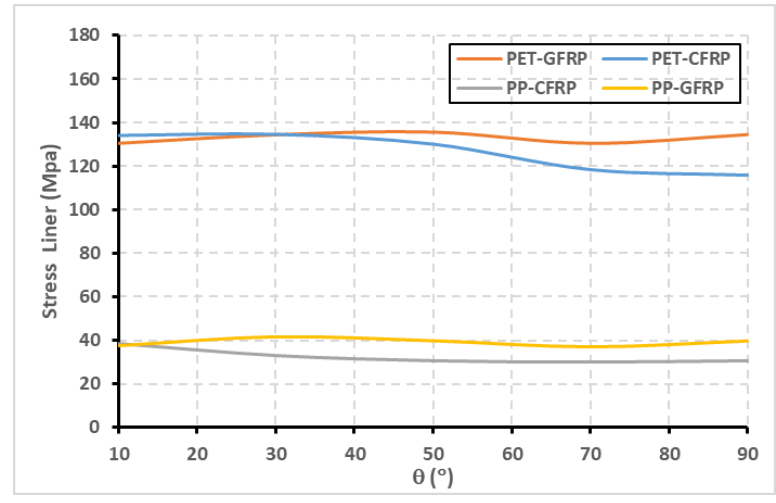

(e)

Figure 15. Maximum stress on the liner with various stacking sequences: (a) $[90 / \pm \theta]_{4 s},(\mathbf{b})[ \pm \theta]_{6 s}$, (c) $[90 / \pm \theta / 90]_{3 s}$, (d) $[0 / \pm \theta]_{4 s}$, and (e) $[0 / \pm \theta / 90]_{3 s}$.

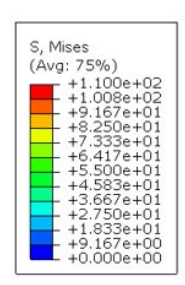

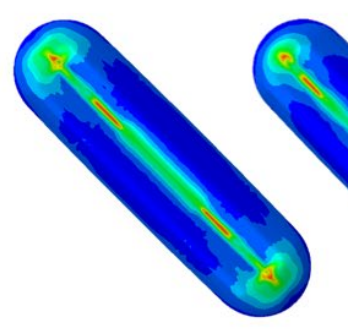

$[90 / \pm 10 / 90]_{35}$

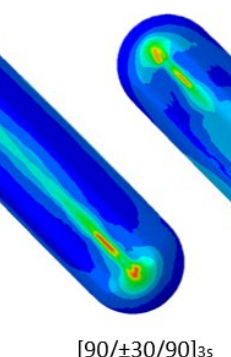

$[90 / \pm 30 / 90]_{35}$

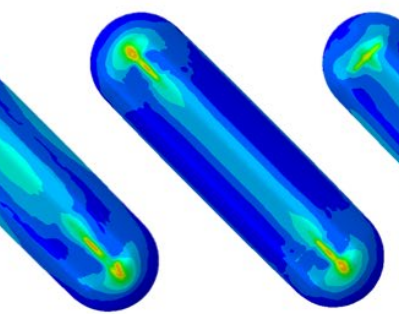

$[90 / \pm 70 / 90]_{3 s}$

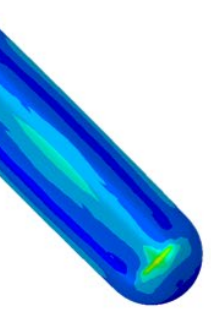

$[90 / \pm 90 / 90] 35$

Figure 16. Stress distribution on the liner (PET).

For all material combinations using PET liner, it is shown that a stacking sequence of $[90 / \pm \theta / 90]_{3 \mathrm{~s}}$ is considered the best option because the composite has a larger number of plies with a winding angle of $90^{\circ}$, resulting in a higher potential to prevent the penetration of the wedge and, thus, the liner experiences lower stress. This also applies to the case of material combination with PP liner. However, for the composition with PP liner, the curve looks flatter for various $\theta$. This happens because PP has lower yield strength and lower strain hardening curve. Therefore, the impact energy is dominantly absorbed by composite rather than the PP liner itself.

The pressure vessel with CFRP composite skin tends to produce lower maximum stress in its liner, compared to the ones with GFRP composite skin. It is because CFRP has stronger mechanical properties than GFRP. However, the difference between CFRP and GFRP is not significant. At a stacking sequence of $[90 / \pm \theta / 90]_{3 \mathrm{~s}}$ with $\theta=90^{\circ}$, the difference between CFRP and GFRP is only about $2-3 \%$. The lowest value of maximum stress in PET-CFRP with this stacking sequence is $103 \mathrm{MPa}$, while PET-GFRP is $105.5 \mathrm{MPa}$. On the other hand, the lowest value of maximum stress of PP-CFRP with this stacking sequence is $27.55 \mathrm{MPa}$, while PP-GFRP is $33 \mathrm{MPa}$.

Examining the structural response, Figure 16 shows the stress contour on PET liner under impact in stacking sequence of $[90 / \pm \theta / 90]_{3 s}$. When the pressure vessel impacts the wedges, the most critical area on the liner is at the joint between the dome and the cylinder body. In this area, there is a contour shift from straight on cylinder body to curvature on the dome. This causes a significant change in the area exposed to impact by wedges. Therefore, in this area, the stress is concentrated and, thus, the contour is colored as red, indicating high stress.

At $\theta=90^{\circ}$, the stress distribution on the liner is widened to the hoop direction at the joint, while there is no noteworthy stress in the middle of the pressure vessel along the longitudinal axis. When $\theta=70^{\circ}$, the stress at the joint is not widened to the hoop, and the stress starts to distribute to 
the center of the vessel. However, there is still no noteworthy stress that exists at the center. As $\theta$ decreases, the stress in the longitudinal axis increases, especially for $\theta=50^{\circ}, 30^{\circ}$, and $10^{\circ}$.

\subsubsection{Energy Dissipation}

Under high-velocity impact loading, the kinetic energy of the impacting body will be partly converted to other forms of energy, such as plastic deformation, elastic strain energy, friction, and also energy dissipation by damage that occurs on the impacted body. Figure 17a illustrates the comparison of energy dissipation by composite damage for various values of $\theta$ with stacking sequence $[90 / \pm \theta / 90]_{3 s}$. These data are obtained from the Abaqus ALLDMD parameter output. A stacking sequence of $[90 / \pm \theta / 90]_{3 \mathrm{~s}}$ is selected because it is the optimum stacking sequence in this load case.

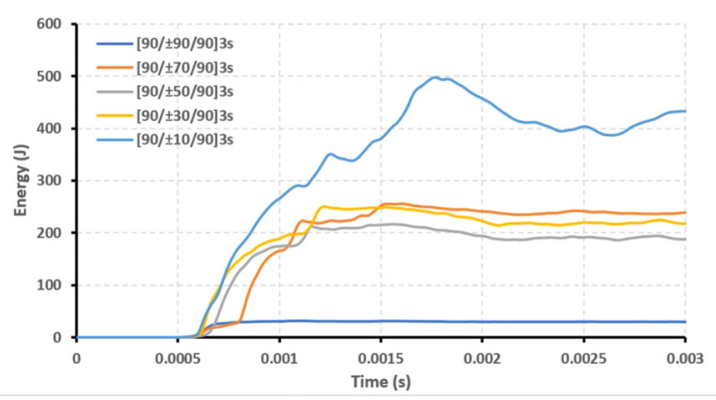

(a)

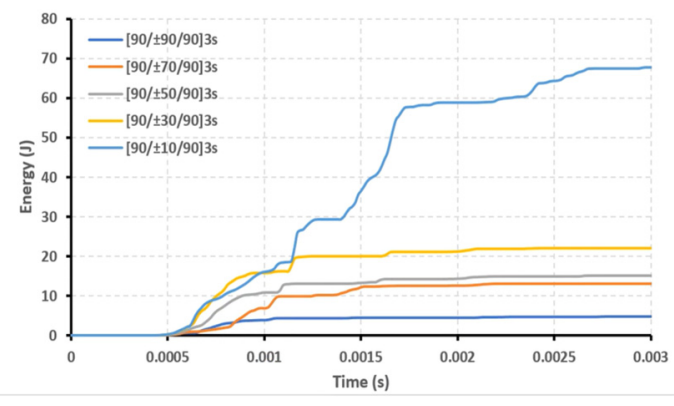

(b)

Figure 17. Energy dissipation in pressure vessel of CFRP-PET for a $[90 / \pm \theta / 90]_{3 s}$ in various $\theta$ by: (a) damage and (b) plastic deformation.

For the current model in which the total composite plies are 24, the damage occurs only on the composite since it is the outer side of the pressure vessel, and no damage occurs in the liner because the maximum stress in liner still under its maximum strength. It can be observed that, for all stacking sequences, the damage starts almost at the same time. For a stacking sequence of $[90 / \pm 10 / 90]_{3 \mathrm{~s}}$, the damage starts first at $4.6 \times 10^{-4} \mathrm{~s}$, while the other stacking sequences start at $5 \times 10^{-4} \mathrm{~s}$. After damage is initiated, the damage value then increases in a stepwise fashion. Stacking sequence of $[90 / \pm 90 / 90]_{3 \mathrm{~s}}$ has the lowest energy of $31.7 \mathrm{~J}$. While for stacking sequences of $[90 / \pm 70 / 90]_{3 \mathrm{~s}}$, $[90 / \pm 50 / 90]_{3 \mathrm{~s}}$, and $[90 / \pm 30 / 90]_{3 \mathrm{~s}}$, the energy dissipations by damage are $221.4,204$, and $205 \mathrm{~J}$, respectively. Furthermore, a stacking sequence of $[90 / \pm 10 / 90]_{3 s}$ has the highest energy of $292 \mathrm{~J}$.

Figure $17 \mathrm{~b}$ shows a plastic deformation that takes place on the pressure vessel gained from the Abaqus all plastically-dissipated (ALLPD) output parameter. In the beginning, the damage starts initially almost at the same time for all stacking sequences, and then it increases. From $15 \times 10^{-4} \mathrm{~s}$, almost all of the curve is flattening out except for the stacking sequence of $[90 / \pm 10 / 90]_{3 s}$. The stacking sequence of $[90 / \pm 90 / 90]_{3 \mathrm{~s}}$ has the lowest energy of $4.8 \mathrm{~J}$, while, for stacking sequences of $[90 / \pm 70 / 90]_{3 \mathrm{~s}}$, $[90 / \pm 50 / 90]_{3 \mathrm{~s}}$, and $[90 / \pm 30 / 90]_{3 \mathrm{~s}}$, the energy dissipation by damage are $13.1,15.1$, and $22 \mathrm{~J}$, respectively. Moreover, the highest energy is obtained with the stacking sequence of $[90 / \pm 10 / 90]_{3 s}$, which is $67.6 \mathrm{~J}$.

A stacking sequence of $[90 / \pm 90 / 90]_{3 \mathrm{~s}}$ has the minimum energy dissipation by damage and less energy dissipation by plastic deformation. It means that this stacking sequence can better withstand the impact load than the other sequences. However, the stress distribution in the liner is wider at the joint between the dome and the cylinder of pressure vessel, and it is prone to the dome because there is only one orientation, which is the hoop direction. No fiber holds the dome in the longitudinal direction. Therefore, it is better to choose another orientation with no significant difference in the maximum stress value, energy dissipation by damage, and energy dissipation by plastic deformation.

Figure 18 shows the comparison of dissipated energy for all material combinations with stacking sequence of $[90 / \pm 90 / 90]_{3 s}$. Vessels with GFRP composite skin dissipate more energy into damage, while vessels with PP liner dissipate more energy into plastic deformation. The energy dissipation by 
damage for PET-GFRP and PP-GFRP is 59.8 and $51.4 \mathrm{~J}$, respectively. On the other hand, lower energy dissipation by damage is obtained when CFRP is employed as a composite. Combinations of PP-CFRP and PET-CFRP have energy dissipation by damage of 33.9 and $31.7 \mathrm{~J}$, respectively.

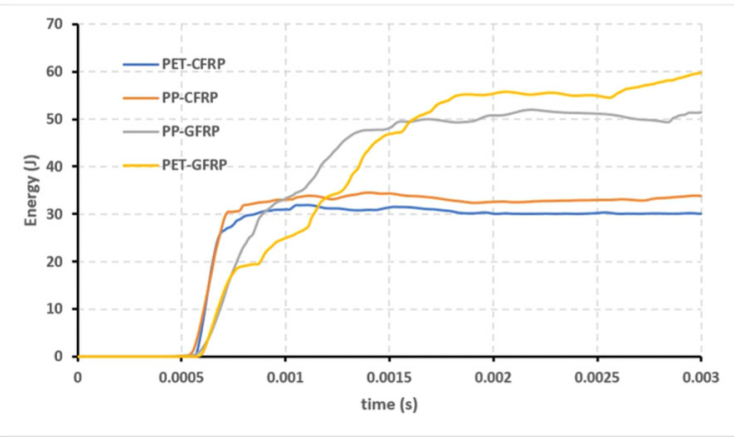

(a)

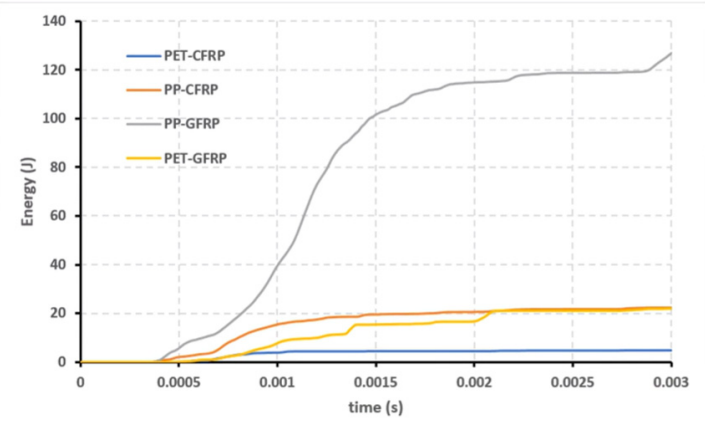

(b)

Figure 18. Comparison of energy dissipation for all material combinations with stacking sequence of [90/ $\pm 90 / 90]_{3 \mathrm{~s}}$ by: (a) damage and (b) plastic deformation.

Further observation on all ALLPD curves leads to the conclusion that using PP as a liner will deserve a higher energy dissipation by plastic deformation, especially for PP-GFRP with the energy dissipation of $126 \mathrm{~J}$. In addition, for PP-CFRP, the energy dissipation by plastic deformation is not as high as PP-GFRP, which is $22.3 \mathrm{~J}$, because the CFRP is sufficiently strong to withstand the impact load. Moreover, using PET as a liner results in less energy dissipation following plastic deformation, which is 21.8 and $4.8 \mathrm{~J}$ for PET-GFRP and PET-CFRP, respectively.

Figures 17 and 18 are the results with the assumption that there are perfect bonding interactions between each plies of composite and also between liner and composite. An additional case study has been conducted to figure out the delamination effect to damage energy dissipation. A model was created with 24 plies of $[90 / \pm 90 / 90]_{3 \mathrm{~s}} \mathrm{CFRP}$ and PET as a liner using cohesive element.

The cohesive element is modeled with Benzeggagh-Kenane (B-K) power of 1.4. From Figure 19, the damage energy dissipation in the model with cohesive elements is higher (114.4 J) than the model without cohesive elements ( $31.8 \mathrm{~J}$ ). This is because the fiber is already delaminated from the structure and loses part of its strength. The composite delamination can be observed in Figure 20. Because of this effect, the maximum von Mises stress on liner with cohesive element is higher (160 MPa) than the model without cohesive element (132 MPa). However, this value is still sufficiently safe and fulfills the requirements because it is lower than the liner ultimate tensile strength. Although the calculated energy dissipations shown in Figures 17 and 18 include no consideration about the delamination effect, these studies are still important and useful to show the comparison of dissipated energy among different angle configurations.

\subsubsection{Failure Mode Composite}

Figure 21 illustrates the failure mode of the outer ply of CFRP composite under impact loading. By visualizing the Hashin damage, both the damaged area and the type of damage can be observed. For the stacking sequence of $[90 / \pm 90 / 90]_{3 s}$, the composite fiber is not damaged at all, and the fiber is strong enough to withstand the impact load. However, its matrix is damaged due to both compression and tension. Furthermore, the fiber composites of the other stacking sequence are damaged by compression, and the matrix is also damaged due to both compression and tension. In addition, when $\theta$ approaches $90^{\circ}$, the damaged area due to compression in the matrix increases. 


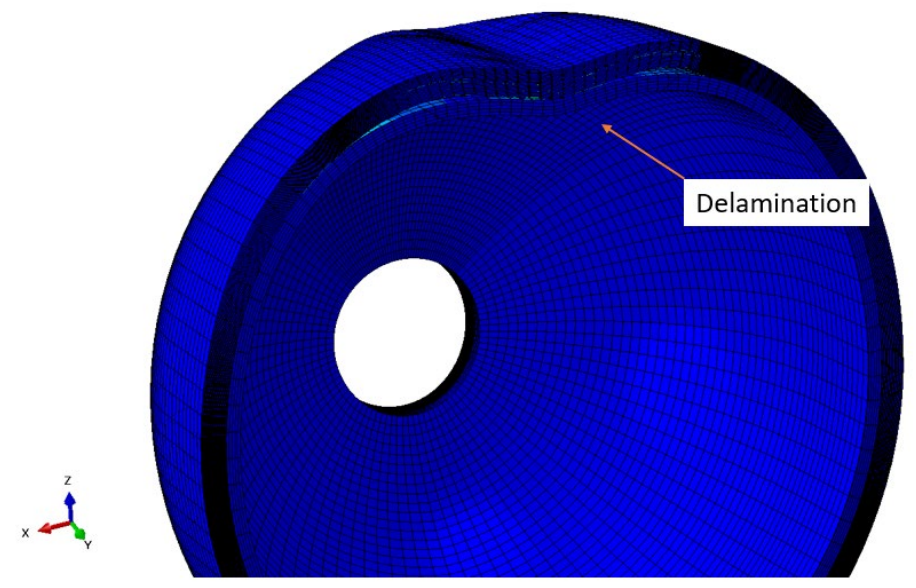

Figure 19. Comparison of damage energy dissipation between the models with and without delamination.

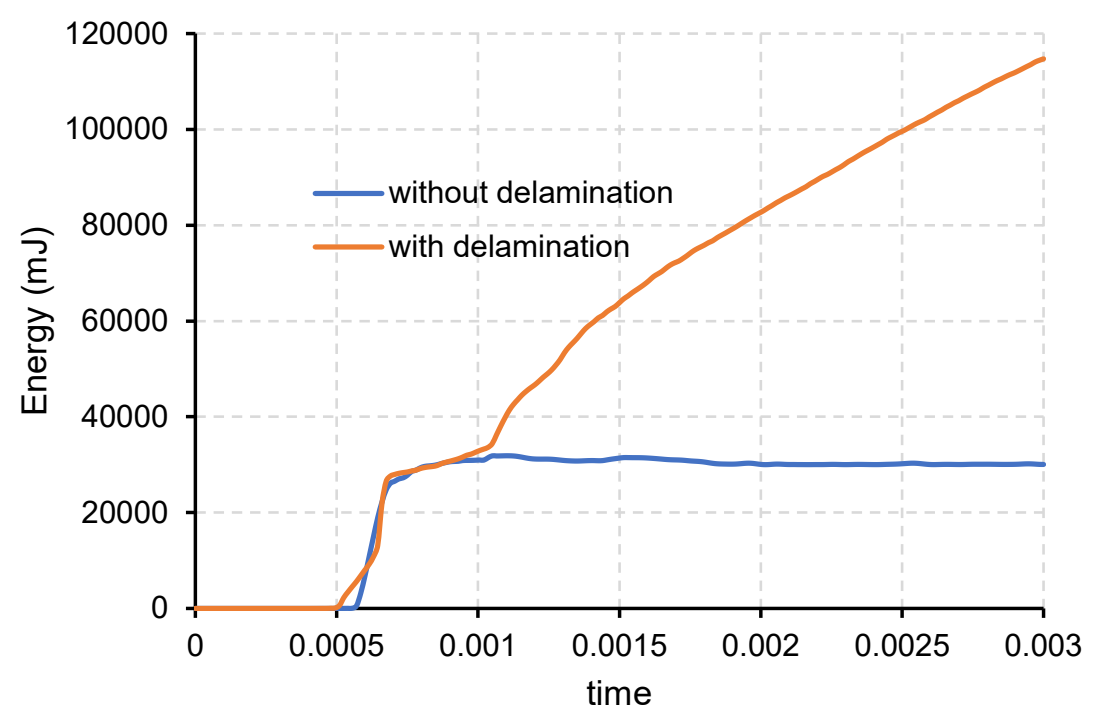

Figure 20. Delamination on pressure vessel with $[90 / \pm 90 / 90]_{3 \mathrm{~s}}$ of PET-CFRP.
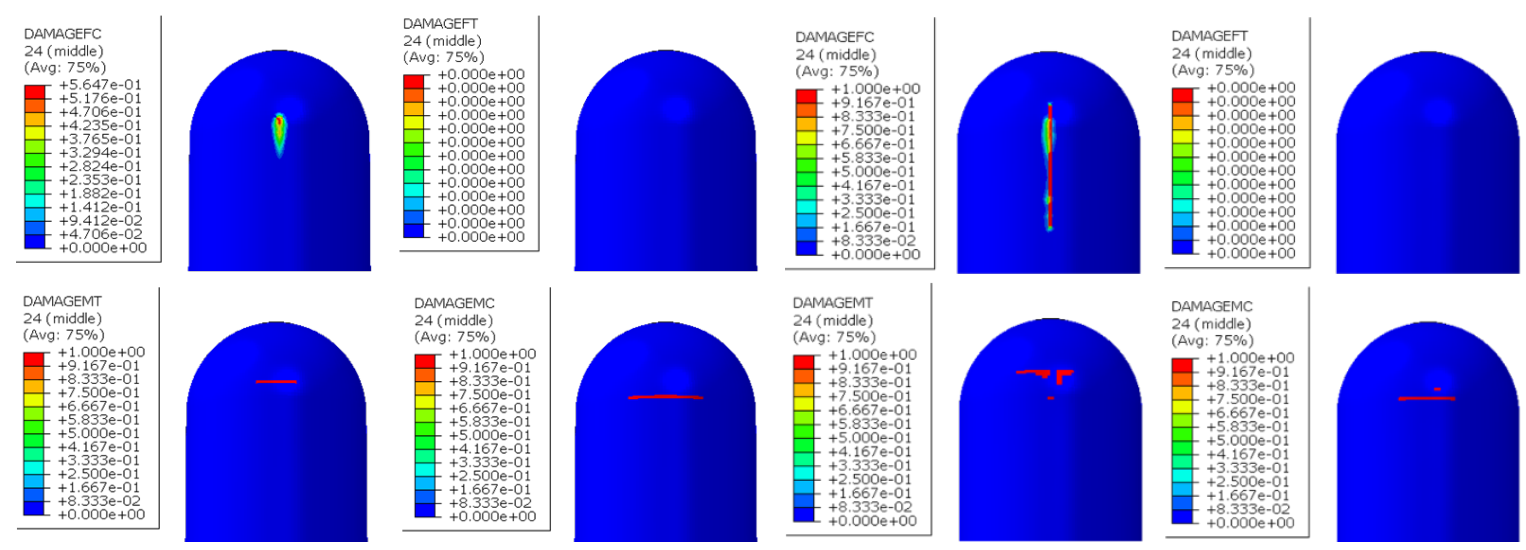

(a)
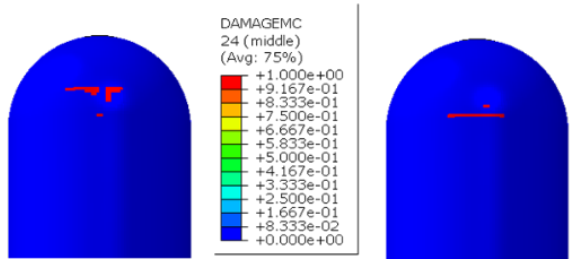

(b)

Figure 21. Cont. 

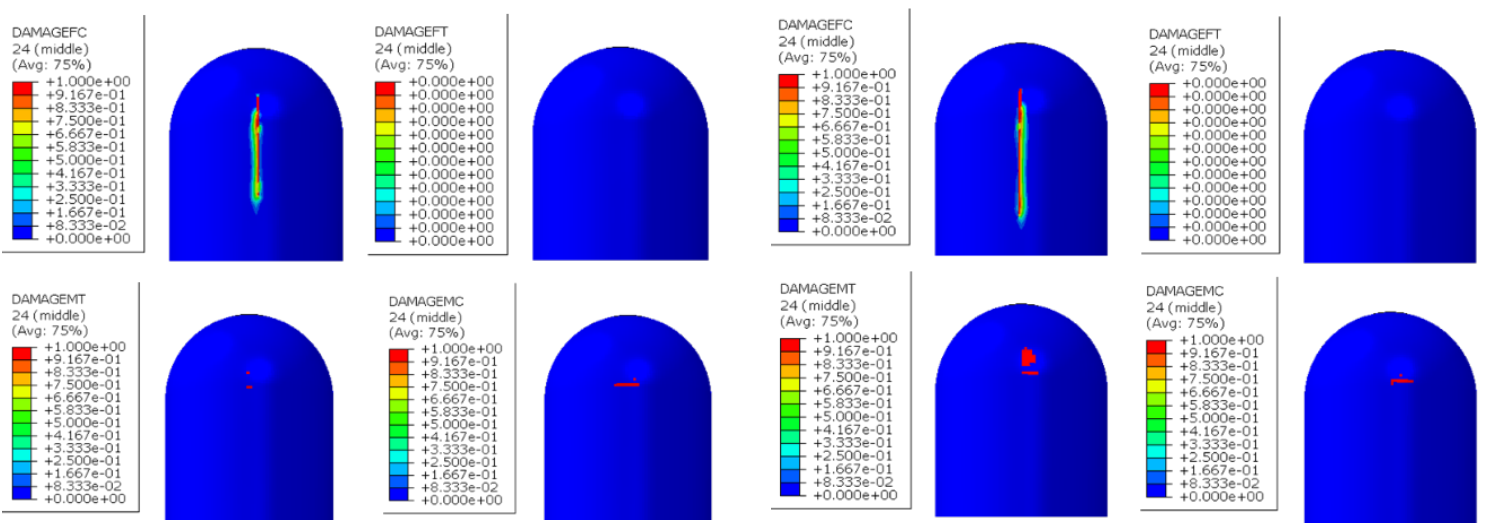

(c)

(d)

Figure 21. Hashin damage on CFRP composite in $[90 / \pm \theta / 90]_{3 \mathrm{~s}}$ for several $\theta$ : (a) 90, (b) 70, (c) 50, and (d) 30 .

\section{Conclusions}

The type-IV pressure vessels for ammonia storage for vehicle purposes have been modeled using finite element modeling by Abaqus software. The developed and modeled pressure vessels have a polymer as a liner, and it is overwrapped by fiber-reinforced composite material to strengthen the structure. There are four types of pressure vessels based on the material combination, which are PET-CFRP, PP-CFRP, PET-GFRP, and PP-GFRP. The designed pressure vessels have a diameter and length of 24 and $90.2 \mathrm{~cm}$, respectively, considering the available space in the automobile and referring to the hydrogen tank that is already available in the market. All the models are simulated under burst and impact loads, referring to regulations of FMVSS 304 and UN/ECE No. 67, respectively.

For the burst test, the result shows that all the material combinations have a similar tendency for each stacking sequence. Utilizing PET as liner material results in higher stress for every lay-up and lower safety factor of liner compared to the material's ultimate strength than using PP as liner material. In addition, using CFRP as composite gives lower stress, resulting in lower thickness needed on pressure vessel design than GFRP. A similar tendency is also obtained for the impact test. For the burst test, the optimum stacking sequences are different for each material combination. Stacking sequences of $[0 / \pm 70 / 90]_{3 s},[0 / \pm 90]_{4 s},[90 / \pm 30 / 90]_{3 s}$, and $[0 / \pm 90]_{4 s}$ are considered the optimum stacking sequences for PET-GFRP, PET-CFRP, PP-CFRP, and PP-GFRP, correspondingly, while, for the impact test, for vessels with PET liner, the stacking sequence of $[90 / \pm \theta / 90]_{3 s}$ is considered the best option, as it shows higher potential to prevent the penetration of the wedge and, hence, lower stress at the liner. Furthermore, for vessels with PP liner, the stress tends to be similar for various $\theta$, because PP has lower yield strength and a lower strain hardening curve. Therefore, the impact energy is dominantly absorbed by composite rather than the PP liner itself.

However, it is considered infeasible to have a pressure vessel with winding angles of $0^{\circ}$ and $90^{\circ}$ due to difficulty during the manufacturing. Therefore, the stacking sequence of $[ \pm \theta]_{6 s}$ is considered the most applicable for manufacturing. For the burst test, $\theta=50^{\circ}$ is considered a the most optimum winding angle, while, for the impact test, a higher winding angle is preferred to achieve lower stress at the liner.

For further analysis and development toward the real application and deployment of the pressure vessel, further research is needed, such as the modeling of the impact in other or multi-directions, clear justification on the optimal value of $\theta$, and other required physical tests (e.g., bonfire, permeation, ammonia cycling, drop, and accelerate stress rupture tests) using the actually developed ammonia pressure vessel. Furthermore, techno-economic analysis is also required to obtain the most optimum and feasible type-IV pressure vessel designed for ammonia. 
Author Contributions: Conceptualization, A.R., H.S.P. and M.A.; methodology, A.R. and H.S.P.; validation, A.R. and H.S.P.; formal analysis, A.R. and H.S.P.; writing-original draft preparation, A.R. and H.S.P.; writing-review and editing, A.R., H.S.P., S.P.S. and M.A.; supervision, S.P.S. and M.A. All authors have read and agreed to the published version of the manuscript.

Funding: This research received no external funding.

Acknowledgments: The authors would like to deeply thank Ditho Pulungan for his very valuable support, especially during the modeling and results discussion.

Conflicts of Interest: The authors declare no conflict of interest.

\section{References}

1. IPCC. Proposed Outline of the Special Report in 2018 on the Impacts of Global Warming of $1.5^{\circ} \mathrm{C}$ Above Pre-Industrial Levels and Related Global Greenhouse Gas Emission Pathways, in the Context of Strengthening the Global Response to the Threat of Climate Cha; IPCC: Geneva, Switzerland, 2018; Volume 2.

2. Allen, M.R.; Dube, O.P.; Solecki, W.; Aragón-Durand, F.; Cramer, W.; Humphreys, S.; Kainuma, M.; Kala, J.; Mahowald, N.; Mulugetta, Y.; et al. IPCC: Framing and Context; IPCC: Geneva, Switzerland, 2018.

3. IPCC. Summary for Policymakers. In Climate Change 2014, Mitigation of Climate Change. Contribution of Working Group III to the Fifth Assessment Report of the Intergovernmental Panel on Climate Change; Edenhofer, O.R., Pichs-Madruga, Y., Sokona, E., Farahani, S., Kadner, K., Seyboth, A., Adler, I., Baum, S., Brunner, P., Eickemeier, B., et al., Eds.; Cambridge University Press: Cambridge, UK, 2014; ISBN 9781107661820.

4. Dutta, S. A review on production, storage of hydrogen and its utilization as an energy resource. J. Ind. Eng. Chem. 2014, 20, 1148-1156. [CrossRef]

5. Møller, K.T.; Jensen, T.R.; Akiba, E.; Li, H. wen Hydrogen-A sustainable energy carrier. Prog. Nat. Sci. Mater. Int. 2017, 27, 34-40. [CrossRef]

6. Aziz, M.; Putranto, A.; Biddinika, M.K.; Wijayanta, A.T. Energy-saving combination of N2 production, NH3 synthesis, and power generation. Int. J. Hydrogen Energy 2017, 42, 27174-27183. [CrossRef]

7. Roszak, R.; Firlej, L.; Roszak, S.; Pfeifer, P.; Kuchta, B. Hydrogen storage by adsorption in porous materials: Is it possible? Colloids Surfaces A Physicochem. Eng. Asp. 2016, 496, 69-76. [CrossRef]

8. Andersson, J.; Grönkvist, S. Large-scale storage of hydrogen. Int. J. Hydrogen Energy 2019, 44, 11901-11919. [CrossRef]

9. Wijayanta, A.T.; Aziz, M. Ammonia production from algae via integrated hydrothermal gasification, chemical looping, N2 production, and NH3 synthesis. Energy 2019, 174, 331-338. [CrossRef]

10. Asia Biomass Office Using Hydrogen Compounds as Renewable Energy Carriers. Available online: https: //www.asiabiomass.jp/english/topics/1512_05.html (accessed on 9 March 2018).

11. Wijayanta, A.T.; Oda, T.; Purnomo, C.W.; Kashiwagi, T.; Aziz, M. Liquid hydrogen, methylcyclohexane, and ammonia as potential hydrogen storage: Comparison review. Int. J. Hydrogen Energy 2019, 44, 15026-15044. [CrossRef]

12. Garagounis, I.; Kyriakou, V.; Anagnostou, C.; Bourganis, V.; Papachristou, I.; Stoukides, M. Solid electrolytes: Applications in heterogeneous catalysis and chemical cogeneration. Ind. Eng. Chem. Res. 2011, 50, 431-472. [CrossRef]

13. Cui, B.; Yu, Z.; Liu, S.; Zhang, J.; Liu, X.; Liu, C.; Zhang, Z. Highly selective and efficient ammonia synthesis from $\mathrm{N} 2$ and $\mathrm{H} 2 \mathrm{O}$ via an iron-based electrolytic-chemical cycle. Int. J. Hydrogen Energy 2020, 45, 94-102. [CrossRef]

14. Dincer, I.; Zamfirescu, C. A review of novel energy options for clean rail applications. J. Nat. Gas Sci. Eng. 2016, 28, 461-478. [CrossRef]

15. Dimitriou, P.; Javaid, R. A review of ammonia as a compression ignition engine fuel. Int. J. Hydrogen Energy 2020, 45, 7098-7118. [CrossRef]

16. Ezzat, M.; Dincer, I. Exergoeconomic analysis and optimization of a new hybrid fuel cell vehicle. Int. J. Hydrogen Energy 2020, 45, 5734-5744. [CrossRef]

17. Chu, Y.; Wu, Y.; Chen, J.; Zheng, S.; Wang, Z. Design of energy and materials for ammonia-based extended-range electric vehicles. Energy Procedia 2019, 158, 3064-3069. [CrossRef]

18. Zamfirescu, C.; Dincer, I. Ammonia as a green fuel and hydrogen source for vehicular applications. Fuel Process. Technol. 2009, 90, 729-737. [CrossRef] 
19. Kishimoto, M.; Muroyama, H.; Suzuki, S.; Saito, M.; Koide, T.; Takahashi, Y.; Horiuchi, T.; Yamasaki, H.; Matsumoto, S.; Kubo, H.; et al. Development of 1 kW-class Ammonia-fueled Solid Oxide Fuel Cell Stack. Fuel Cells 2020, 20, 1-9. [CrossRef]

20. Zhao, Y.; Setzler, B.P.; Wang, J.; Nash, J.; Wang, T.; Xu, B.; Yan, Y. An Efficient Direct Ammonia Fuel Cell for Affordable Carbon-Neutral Transportation. Joule 2019, 3, 2472-2484. [CrossRef]

21. Kobayashi, H.; Hayakawa, A.; Somarathne, K.D.K.A.; Okafor, E.C. Science and technology of ammonia combustion. Proc. Combust. Inst. 2019, 37, 109-133. [CrossRef]

22. Duijm, N.J.; Markert, F.; Paulsen, J.L. Safety Assessment of Ammonia as a Transport Fuel; Risø National Laboratory: Roskilde, Denmark, 2005; ISBN 8755034152.

23. World LPG Association. AUTOGAS Vehicles Catalogue 2018; World LPG Association: Neuilly-sur-Seine, France, 2018.

24. Shiozawa, F. Energy Carriers that Open Up a Hydrogen Society. Available online: http://ieei.or.jp/2015/05/ exp1150501/ (accessed on 7 July 2020).

25. Propane Education \& Research Council. Cylinder Requalification; Propane Education \& Research Council: Washington, DC, USA, 2019.

26. Kamal, A.M.; El-Sayed, T.A.; El-Butch, A.M.A.; Farghaly, S.H. Analytical and finite element modeling of pressure vessels for seawater reverse osmosis desalination plants. Desalination 2016, 397, 126-139. [CrossRef]

27. Wong, J. CNG and Hydrogen Tank Safety, RED, and Testing; Powertech Labs Inc.: Surrey, BC, Canada, 2009.

28. Aziz, M.; Wijayanta, A.T.; Nandiyanto, A.B.D. Ammonia as Effective Hydrogen Storage: A Review on Production, Storage and Utilization. Energies 2020, 13, 3062. [CrossRef]

29. Samsun, R.C.; Antoni, L.; Rex, M. Advanced Fuel Cells Technology Collaboration Programme Report on Mobile Fuel Cell Application: Tracking Market Trends; IEA Technoogy Collaboration Programme: Paris, France, 2020.

30. PDH Center. ASME Section I E Section VIII: Fundamentals. PDHonline Course M398; PDH Center: Fairfax, VA, USA, 2012.

31. Lawate, S.; Deshmukh, B.B. Analysis of Heads of Pressure Vessel. Int. J. Innov. Res. Sci. Eng. Technol. 2015, $4,759-765$.

32. Zhang, Q.; Xu, H.; Jia, X.; Zu, L.; Cheng, S.; Wang, H. Design of a 70 MPa type IV hydrogen storage vessel using accurate modeling techniques for dome thickness prediction. Compos. Struct. 2020, 236, 111915. [CrossRef]

33. Hua, T.Q.; Ahluwalia, R.K.; Peng, J.-K.; Kromer, M.; Lasher, S.; McKenney, K.; Law, K.; Sinha, J. Technical assessment of compressed hydrogen storage tank systems for automotive applications. Int. J. Hydrogen Energy 2011, 36, 3037-3049. [CrossRef]

34. Essentra plc Caps and Plugs: How do HDPE and PP Compare? Available online: https://www. essentracomponents.com/en-us/news/product-resources/caps-and-plugs-how-do-hdpe-and-pp-compare (accessed on 20 June 2020).

35. The Plastic Bottles Company Properties of HDPE, LDPE and PET Bottles. Available online: https://blog. theplasticbottlescompany.com/general/articles/properties-hdpe-ldpe-pet-bottles/ (accessed on 20 June 2020).

36. Pulungan, D.; Yudhanto, A.; Goutham, S.; Lubineau, G.; Yaldiz, R.; Schijve, W. Characterizing and modeling the pressure- and rate-dependent elastic-plastic-damage behavior of polypropylene-based polymers. Polym. Test. 2018, 68, 433-445. [CrossRef]

37. Gupta, S.; Sharma, K.; Saxena, N.S. Temperature Dependent Mechanical Analysis of Chalcogenide (CdS, ZnS) Coated PET Films. ISRN Polym. Sci. 2013, 2013, 1-7. [CrossRef]

38. Tie, Y.; Zhang, Q.; Hou, Y.; Li, C. Impact damage assessment in orthotropic CFRP laminates using nonlinear Lamb wave: Experimental and numerical investigations. Compos. Struct. 2020, 236, 111869. [CrossRef]

39. Wu, Q.; Zhi, X.; Li, Q.; Guo, M. Experimental and numerical studies of GFRP-reinforced steel tube under low-velocity transverse impact. Int. J. Impact Eng. 2019, 127, 135-153. [CrossRef]

40. De Camargo, E.J.; Moreschi, E.; Baseggio, W.; Cury, J.A.; Pascotto, R.C. Composite depth of cure using four polymerization techniques. J. Appl. Oral Sci. 2009, 17, 446-450. [CrossRef]

41. Wang, D.; Liao, B.; Zheng, J.; Huang, G.; Hua, Z.; Gu, C.; Xu, P. Development of regulations, codes and standards on composite tanks for on-board gaseous hydrogen storage. Int. J. Hydrogen Energy 2019, 44, 22643-22653. [CrossRef] 
42. United Nations Economic Commission for Europe. Requirements for the Installation of Specific Equipment for the Use of Liquefied Petroleum Gases in the Propulsion System of a Vehicle; United Nations Economic Commission for Europe: Geneva, Switzerland, 2012.

43. National Highway Traffic Safety Administration (NHTSA) Section 571.304 of the Federal Motor Vehicle Safety Standards: Compressed Natural Gas Fuel Container Integrity. Available online: https://www.ecfr.gov/ cgi-bin/text-idx?SID=7d443eb75ceba033fed91e90f816b574\&node=se49.6.571_1304\&rgn=div8 (accessed on 20 June 2020).

44. Dassault Systèmes Simulia. Abaqus CAE User's Manual (6.12); Dassault Systèmes Simulia: Providence, RI, USA, 2012.

45. Gentilleau, B.; Touchard, F.; Grandidier, J.C. Numerical study of influence of temperature and matrix cracking on type IV hydrogen high pressure storage vessel behavior. Compos. Struct. 2014, 111, 98-110. [CrossRef]

46. Zu, L.; Xu, H.; Jia, X.; Zhang, Q.; Wang, H.; Zhang, B. Winding path design based on mandrel profile updates of composite pressure vessels. Compos. Struct. 2020. [CrossRef]

47. Ariyama, T.; Mori, Y.; Kaneko, K. Tensile Properties and Stress Relaxation of Polypropylene at Elevated Temperatures. Polym. Eng. Sci. 1997, 37, 81-90. [CrossRef]

(C) 2020 by the authors. Licensee MDPI, Basel, Switzerland. This article is an open access article distributed under the terms and conditions of the Creative Commons Attribution (CC BY) license (http://creativecommons.org/licenses/by/4.0/). 